\title{
Unemployment History and Frictional Wage Dispersion
}

\author{
Victor Ortego-Marti*
}

This version: September 6, 2014

\begin{abstract}
This paper studies wage dispersion among identical workers in a random matching search model in which workers lose human capital during unemployment. Wage dispersion increases, as workers accept lower wages to avoid long unemployment spells. The model is an important improvement over baseline search models. It explains between a third and half of the observed residual wage dispersion. When adding on-the-job search, the model accounts for all of the residual wage dispersion and generates substantial dispersion even for high values of non-market time. The paper thus addresses the trade-off between explaining frictional wage dispersion and the cyclical behavior of unemployment.
\end{abstract}

\footnotetext{
*Department of Economics, University of California Riverside. Sproul Hall 3132, Riverside CA 92521. Email: victor.ortego-marti@ucr.edu. Phone: 951-827-1502. I am extremely grateful to the associate editor François Gourio, an anonymous referee, Wouter den Haan, Jang-Ting Guo, Per Krusell, Adrian Masters, Pascal Michaillat, Dale Mortensen, Rachel Ngai, Chris Pissarides, Yonna Rubinstein, Carlos Thomas, Gianluca Violante and Alwyn Young for their valuable comments and suggestions. I also thank Francesco Caselli, Yu-Chin Chen, Daniele Coen-Pirani, James Costain, Joel David, Fabio Ghironi, Marcus Hagedorn, Jonathan Heathcote, Ethan Ilzetzki, Philip Jung, John Kennan, Nicholas Kiefer, Philip Kircher, Rasmus Lentz, Vincenzo Quadrini, Valery Ramey, Guillaume Rocheteau, Shouyong Shi, Murat Tasci, Silvana Tenreyro, Stephen Turnovsky, Guillaume Vandenbroucke, Ludo Visschers, Carl Walsch, Joel Watson, Linda Yuet-Yee and seminar participants at the 2012 Cycles, Adjustment, and Policy Conference on Credit, Unemployment, and Frictions at Sandbjerg Gods, Aarhus University, the 2012 French Economic Association Meeting, the 11th New York/Philadelphia Workshop on Quantitative Macroeconomics, the 6th Southwest Search and Matching Workshop, Bank of Spain, Dutch Central Bank, London School of Economics, UC Riverside, UC San Diego, UC Santa Cruz, University of Southern California and University of Washington for helpful discussions. Financial support from the Bank of Spain and the Fundacion Ramon Areces is gratefully acknowledged.
} 


\section{Introduction}

A large number of papers in labor economics explore the determinants of wages. The effects on wages of worker characteristics, such as education or tenure, are well documented. However, worker characteristics can only explain a fraction of the observed wage dispersion in the data. Once one controls for these characteristics, the residual still displays a large amount of dispersion. Therefore, observationally similar workers are paid different wages.

Search models of the labor market can explain why apparently similar workers are paid different wages. In these models, workers adopt a reservation wage strategy when looking for jobs. Job offers are only available with a given frequency, so workers accept a job offer if the associated wage is above their reservation value. This acceptance rule by workers generates wage dispersion, even among identical workers. ${ }^{1}$ However, recent work by Hornstein, Krusell \& Violante (2011) shows that baseline search models fail to generate significant wage dispersion. The authors use the ratio between the mean and minimum wage observation, the mean-min or $M m$ ratio, to measure wage dispersion. In search models the $M m$ ratio is a function of labormarket flows and preference parameters, for which reliable estimates exist. These estimates imply an $M m$ ratio in search models of around 1.05, implying that the mean wage is $5 \%$ higher than the minimum observed wage. By contrast, the residual in a Mincerian regression, with as many controls as possible, gives a 50-10 percentile ratio between 1.7 and 1.9. Given that this 50-10 percentile ratio is a reasonable empirical counterpart to the $M m$ ratio, the gap between the two values is remarkable. ${ }^{2}$

This paper introduces a search model in which workers lose some human capital or skills during unemployment. Workers become less productive while they remain unemployed, so wages depend on workers' unemployment histories - their cumulative time spent in unemployment. I use this model to address the following question: What happens to wage dispersion among identical workers if they lose human capital during unemployment? The model generates further wage dispersion compared to baseline search models because workers adjust their search behavior. The intuition is the following. Unemployment "hurts" workers. They lose human capital during unemployment, which depreciates their wages. Since workers are aware that

\footnotetext{
${ }^{1}$ The literature uses the term frictional wage dispersion to describe the wage dispersion among identical workers that arises from search frictions. For example, see Mortensen (2005).

${ }^{2}$ Using the 10th percentile reduces some of the measurement error associated with the minimum observation.
} 
longer unemployment spells lead to larger wage losses, they are willing to accept lower wages to leave unemployment more quickly. With a lower reservation wage, wage dispersion increases among identical workers. ${ }^{3}$

The paper shows that wage dispersion increases significantly if workers lose some human capital during unemployment. I derive an expression of the $\mathrm{Mm}$ ratio in the model that does not rely on any assumption about the underlying distribution of match productivities. The $M m$ ratio is uniquely determined by a set of parameters, for which reliable estimates exist. ${ }^{4}$ To illustrate the amount of wage dispersion generated by the model, I compare its implied $\mathrm{Mm}$ ratio to the one in the baseline search model and the data. Using estimates from the Panel Study of Income Dynamics (PSID), the $M m$ ratio in the model with loss of human capital has a value of 1.15. By contrast, the $M m$ ratio in the baseline search model is 1.04. In the PSID the 50-10 percentile ratio is 1.34. A similar picture emerges if one uses estimates from the Current Population Survey (CPS) for the labor market flows, as given by Shimer (2005). The $M m$ ratio has a value of 1.22 in the model with loss of human capital, whereas for the baseline search model the value is 1.05. Empirically, the 50-10 percentile ratio is between 1.7 and 1.9. These results imply that, while the baseline model explains around $11 \%$ of the residual wage dispersion in the PSID, and $6 \%$ of that in the CPS, the mechanism of the model accounts for around $45 \%$ of the wage dispersion in the PSID, and $28 \%$ of that in the CPS.

The paper then adds on-the-job search to the framework with loss of human capital during unemployment. The $\mathrm{Mm}$ ratio is again uniquely determined by a set of parameters for which reliable estimates exist. I show that adding on-the-job search further increases wage dispersion. ${ }^{5}$ The model with unemployment history and on-the-job delivers a $M m$ ratio of around 2 , thus accounting for all of the observed residual wage dispersion in the CPS. The model also addresses the trade-off found by Hornstein, Krusell \& Violante (2011) between explaining frictional wage dispersion and the unemployment volatility puzzle. Matching the cyclical behavior

\footnotetext{
${ }^{3}$ To avoid repetition I use wage dispersion to refer to wage dispersion among ex-ante identical workers, the focus of the paper.

${ }^{4}$ In their work Hornstein, Krusell \& Violante (2011) find that in most search models one can express the $M m$ ratio as a function of a few parameters.

${ }^{5}$ Hornstein, Krusell \& Violante (2011) show that allowing for on-the-job search improves the performance of search models. The amount of wage dispersion in a search model with on-the-job search has a similar magnitude to that of the model with unemployment history, with an $M m$ ratio between 1.16 and 1.27. Intuitively, the problem with search models is that they predict that workers wait a long time before accepting a job offer. If workers are allowed to search while being employed, they are willing to accept lower offers because they do not give up the option of searching when they accept a job.
} 
of unemployment and vacancies requires high values for non-market time, as measured for example by the replacement ratio-benefits over average wages. However, a high replacement ratio makes the frictional wage dispersion problem worse. I show that even with the highest value in the literature for the replacement ratio, the model with unemployment history and on-the-job search yields a high $M m$ ratio, around 1.68 .

The model incorporates workers' loss of human capital during unemployment in the following way. Workers' human capital depreciates at a constant rate while they stay in unemployment. ${ }^{6}$ This feature is introduced in an otherwise typical search model, the Pissarides (1985) random matching model. Each match between the firm and the worker has a match-specific productivity. In contrast to the standard model, the productivity of the match further depends on the worker's human capital, which is uniquely determined by workers' unemployment history. When the worker and the firm meet, if the match-specific productivity is above a reservation productivity value they start to produce.

I assume that unemployment benefits are proportional to workers' human capital. As a result, benefits gradually decrease while workers stay unemployed. There is no reason to believe that benefits should satisfy this property, but assuming it greatly simplifies the solution. ${ }^{7}$ However, in the paper I also solve the model with constant unemployment benefits, using numerical methods, and show that it generates very similar amounts of wage dispersion. With proportional benefits, a closed form solution exists. The $M m$ ratio is independent of any distributional assumption for match productivities. Evaluating the $M m$ ratio only requires knowledge of a few parameters, namely the depreciation rate of human capital during unemployment, the labor market flow rates, the interest rate, and the replacement ratio.

The paper contains some empirical work to quantify the amount of wage dispersion consistent with the data. I use the PSID, one of the large panels of US workers, to construct workers' unemployment history and estimate the rate at which they lose human capital during unemployment. The regression results indicate that an additional month of unemployment history is associated with around $1.2 \%$ wage loss. Because the model assumes that human capital losses are permanent, the empirical part of the paper shows that these losses are indeed persistent.

\footnotetext{
${ }^{6}$ This human capital should not be confused with the human capital given, for example, by education, which is observable and thus controlled for in Mincerian regressions.

${ }^{7}$ A number of papers use similar assumptions to simplify the derivations. For example, see Mortensen \& Pissarides (1998) or Postel-Vinay \& Robin (2002).
} 
The $M m$ ratio in the model is then compared to the 50-10 percentile ratio of the residual in the Mincerian regression.

Related literature. This paper is motivated by the findings in Hornstein, Krusell \& Violante (2011) that baseline search models fail to generate significant wage dispersion. ${ }^{8}$ The paper is also related to two literatures.

First, a large empirical literature explores the effects of job displacement on workers' earnings. Fallick (1996) and Kletzer (1998) are excellent reviews of the job displacement literature. ${ }^{9}$ The literature finds that job displacement causes large and very persistent earning losses to displaced workers. ${ }^{10}$ The magnitude of the earnings losses are much larger than those of this paper. The difference in their estimates comes from their focus on displaced workers, a smaller set of unemployed workers who usually suffer larger losses. ${ }^{11}$ Using the estimates from the job displacement literature would only increase wage dispersion, so this difference is not problematic. However, the empirical work in this paper is better suited for the model for two reasons. First, only some unemployed workers are displaced. Second, because my empirical work focuses on how the wage loss depends on workers' unemployment history, it provides a better mapping between the empirical estimates and the corresponding variable in the model.

The second literature introduces the loss of human capital during unemployment into search models. Aside from modeling differences, these papers answer different questions. Ljungqvist \& Sargent (1998) offer an explanation for the high unemployment in Europe compared to the US. ${ }^{12}$ Pissarides (1992) finds that unemployment becomes more persistent when unemployed workers lose skills and studies the implications for long term unemployment. Shimer \& Werning (2006), Pavoni \& Violante (2007) and Pavoni (2011) study unemployment insurance. In Burdett,

\footnotetext{
${ }^{8}$ Mukoyama \& Sahin (2009) is another paper that identified the relationship between the job finding rate - or unemployment duration - and wage dispersion. However, they do not explore the capacity of search models to generate significant wage dispersion.

${ }^{9}$ See also Couch \& Placzek (2010) and von Wachter, Song \& Manchester (2009) for more recent results.

${ }^{10}$ Although the size of the earnings losses varies depending on the data source and the period or location studied. Couch \& Placzek (2010), Jacobson, LaLonde \& Sullivan (1993), Schoeni \& Dardia (2003), von Wachter, Song \& Manchester (2009) use administrative data; Ruhm (1991) and Stevens (1997) use the PSID; and Carrington (1993), Farber (1997), Neal (1995), Topel (1990) use the Displaced Worker Survey (DWS).

${ }^{11}$ Displaced workers are a subset of all unemployed workers. The formal definition says that displaced workers are fairly attached to their job and are involuntarily separated from it, with little chance of being recalled by their employer or finding a similar job within a reasonable span of time. To select workers who are attached to their job, the job displacement literature usually focuses on workers with a minimum tenure on a job. The job loss must also be involuntary, so quits, temporary layoffs and firings for cause are not job displacements.

${ }^{12}$ See also the related papers by den Haan, Haefke \& Ramey (2005), and Ljungqvist \& Sargent (2007) and (2008).
} 
Carrillo-Tudela \& Coles (2011) workers accumulate human capital when they are employed, but there is no loss during unemployment. Workers can search on-the-job, and employed and unemployed workers receive job offers at the same rate. ${ }^{13}$ Because they focus on explaining why younger workers move jobs more frequently and are more likely to experience wage gains, they calibrate the parameters taking the empirical $M m$ ratio as a target. ${ }^{14}$ In Coles \& Masters (2000) long-term unemployment arises endogenously. They also introduce training, so workers can recover some of the lost human capital when they start a job. In equilibrium, firms train workers until they regain all of their lost human capital. ${ }^{15}$ Their framework suggests that job creation subsidies are a more efficient policy than training for the unemployed. The question in this paper is different. I implement the effects of unemployment history on wages to explore the capacity of search models to generate wage dispersion.

The paper starts with the model, and continues with the empirical work using the PSID. Next, using numerical methods, I derive the solution for the case of constant benefits during unemployment, which to my knowledge is not a widely used approach. ${ }^{16}$ I show that both models generate very similar amounts of wage dispersion. I then assess the amount of wage dispersion consistent with the CPS. Finally, I incorporate on-the-job search in the model with unemployment history.

\section{The Labor Market}

The model builds on the random matching model of Pissarides (1985). I introduce the assumption that workers gradually lose human capital during unemployment at a constant rate $\delta$. The loss depends on the time the worker spends in unemployment. Throughout the paper the term unemployment history refers to the cumulative duration of unemployment spells. I use $\gamma$ to

\footnotetext{
${ }^{13}$ This assumption of same job offer rates implies very large $M m$ ratios of 2.5 even without human capital accumulation, but it is at odds with the data. Empirically, unemployed workers receive job offers at a much higher rate than employed workers.

${ }^{14}$ Whereas I proceed differently. The $M m$ is not a target in a calibration exercise. The model shows a direct link between the parameters in the model and the dispersion of wages. I estimate the parameters from the data, and use them to quantify the dispersion of wages consistent with those estimates.

${ }^{15}$ Although the empirical evidence shows important wage losses after becoming unemployed. Jacobson, LaLonde \& Sullivan (2005) find that displaced workers regain some lost earnings if they receive training, but they remain far from recovering all lost earnings.

${ }^{16}$ Coles \& Masters (2000) do consider constant benefits during unemployment, but their solution is simplified by the retraining assumption.
} 
denote unemployment history.

Given the focus on residual wage dispersion, human capital in the model is net of other controls such as education. Thus, human capital depends only on unemployment history. I denote workers' human capital by $h(\gamma)$. Normalizing $h(0)=1$, the constant depreciation rate during unemployment implies that human capital is given by $h(\gamma)=e^{-\delta \gamma}$. Workers do not accumulate human capital when they are employed. This assumes that human capital losses are permanent. Section 3 provides empirical support for this assumption and shows that these losses are long-lived. The online technical appendix studies a model in which workers also accumulate human capital when they are employed, so that losses incurred during unemployment are not fully permanent. In this case workers have further incentives to gain employment and wage dispersion increases. ${ }^{17}$

Workers search for jobs, and firms for job applicants. I assume that the worker and the firm draw a productivity parameter $p$ from a known distribution $F(p)$ when they meet. The productivity of the match is determined by the product of the match-specific productivity $p$ and the worker's human capital $h(\gamma)$, i.e. by $h(\gamma) p$.

Following the approach in Pissarides (2000), labor market flows are determined by a matching function $m(V, U)$, where $V$ denotes vacancies and $U$ unemployed workers. Market tightness $\theta$ is defined as the ratio of vacancies to unemployed workers, $\theta=V / U$. I assume the usual conditions for the matching function, that it is increasing in both its arguments and concave, and that it displays constant returns. Workers find jobs at a rate $f(\theta)=m(V, U) / U$, and firms receive applicants at a rate $q(\theta)=m(V, U) / V$. The properties of the matching function imply that $f(\theta)=\theta q(\theta)$. If the labor market is tight ( $\theta$ high, many vacancies for a given number of unemployed workers) workers find jobs more easily, and firms have more difficulty finding applicants. In other words, $\partial f / \partial \theta \geq 0$, and $\partial q / \partial \theta \leq 0$. Separations occur at an exogenous rate $s .{ }^{18}$ The paper only considers the steady-state, so for simplicity I drop $\theta$ from the notation.

Workers are identical when they first join the labor market. However, they find and lose jobs randomly, so in equilibrium they accumulate different unemployment histories. I assume

\footnotetext{
${ }^{17}$ However, most of the increase in wage dispersion comes from the effect of unemployment history. Intuitively, the rate of human capital accumulation must be smaller than the effective rate of return $r+\mu$ for the value functions to be bounded. In a model with human capital accumulation during employment but no loss of skills the $M m$ ratios are still small, as Hornstein et al. (2011) point out and as the appendix shows.

${ }^{18}$ As Hornstein et al. (2011) show, adding endogenous separations increases wage dispersion. However, the results are almost the same as with exogenous separations, because wages are very persistent in data.
} 
that workers leave the labor force at a rate $\mu$, and are replaced by new workers with zero unemployment history. This allows for a stationary distribution of unemployment histories. I denote the distribution of unemployment histories among unemployed workers by $G^{U}(\gamma)$, and among employed workers by $G^{E}(\gamma)$. These distributions are endogenous.

I assume that unemployed workers receive payments $b h(\gamma)$. With this assumption, payments during unemployment are proportional to workers' human capital level $h(\gamma)$, and decrease at the rate $\delta$ while they remain unemployed. This assumption greatly simplifies the analysis, and allows for a closed-form solution. In section 4 , I solve the model with constant $b$ numerically, and assess how this assumption changes the results.

\subsection{Asset equations for workers and firms}

Unemployed workers accept a job if the match-specific productivity is above their reservation productivity. Given that human capital decreases while the worker stays unemployed, the reservation productivity may depend on unemployment history $\gamma$. In section 2.2 I show that Nash Bargaining implies that the reservation productivity is the same for workers and firms. To avoid unnecessary complications in notation, I denote this reservation productivity by $p_{\gamma}^{*}$.

Let $U(\gamma)$ be the value function of an unemployed worker with unemployment history $\gamma$, and $W(\gamma, p)$ the value function of an employed worker in a job with match-specific productivity $p$. If $r$ is the interest rate, the asset equation for the unemployed worker is

$$
(r+\mu) U(\gamma)=b h(\gamma)+f \int_{p_{\gamma}^{*}}^{p^{\max }}(W(\gamma, y)-U(\gamma)) d F(y)+\frac{\partial U(\gamma)}{\partial \gamma}
$$

The left-hand side of (1) represents the returns to being unemployed with unemployment history $\gamma$, taking into account that workers leave the labor force at rate $\mu$ (so $r+\mu$ is the effective discount rate). Consider now the right-hand side. The first term corresponds to the payments workers receive while unemployed. The second term captures the option value of being unemployed, namely that at rate $f$ the worker receives a job offer with expected gain $\int_{p_{\gamma}^{*}}^{p^{\max }}(W(\gamma, y)-U(\gamma)) d F(y)$. The last term captures the capital depreciation of the value of unemployment $U(\gamma)$, caused by the depreciation of human capital while the worker stays unemployed. 
Wages depend on the human capital of the worker and the match-specific productivity. I use $w(\gamma, p)$ to denote the wage of a worker with unemployment history $\gamma$ employed in a job with match-specific productivity $p$. The asset equation for the employed worker is

$$
(r+\mu) W(\gamma, p)=w(\gamma, p)-s(W(\gamma, p)-U(\gamma))
$$

The intuition behind this equation is similar. The worker receives a wage $w(\gamma, p)$, and at a rate $s$ the worker loses the job, which carries a net loss of size $W(\gamma, p)-U(\gamma)$.

To find successful candidates, firms post vacancies at cost $k$. Remember that later I prove that the reservation productivity $p_{\gamma}^{*}$ is the same for firms and workers. So the firm hires a worker with unemployment history $\gamma$ if $p \geq p_{\gamma}^{*}$. The firm receives applications from unemployed workers with $\gamma$ given by the endogenous distribution $G^{U}(\gamma)$. The asset equation for vacancies is

$$
r V=-k+q \int_{0}^{\infty}\left(\int_{p_{\gamma}^{*}}^{p^{\max }}(J(\gamma, y)-V) d F(y)\right) d G^{U}(\gamma)
$$

I assume free entry in the market for vacancies, meaning that firms post vacancies until $V=0$.

When production begins, a worker produces $h(\gamma) p$. Having to pay wages, the firm receives $h(\gamma) p-w(\gamma, p)$. The asset equation for a filled job position is

$$
(r+\mu) J(\gamma, p)=h(\gamma) p-w(\gamma, p)-s(J(\gamma, p)-V)
$$

The intuition is similar. The left-hand side represents the returns to a filled position. The right-hand side captures that the filled position produces a flow $h(\gamma) p-w(\gamma, p)$, and that at rate $s$ the job is destroyed, with a net loss of $J-V$.

\subsection{Reservation productivity and wages}

In the next few paragraphs I find two results about reservation productivities. First, given the assumption that unemployment benefits and the productivity of matches are proportional to human capital, I prove that the reservation productivity $p_{\gamma}^{*}$ is independent of $\gamma$. This simplifies greatly the analysis. Second, I find an expression that links wages and the reservation productivity. 
I assume that wages are determined by Nash Bargaining. When the worker and the firm meet, if $p \geq p_{\gamma}^{*}$ production begins and they split the surplus. Given a bargaining strength $\beta$, the wage is the solution to

$$
w(\gamma, p)=\underset{w(\gamma, p)}{\arg \max }(W(\gamma, p)-U(\gamma))^{\beta}(J(\gamma, p)-V)^{1-\beta} .
$$

The surplus of the match is given by $J(\gamma, p)-V+W(\gamma, p)-U(\gamma)$. Nash Bargaining implies that the worker gets a share $\beta$ of the surplus, and the firm a share $1-\beta$. Combining (5) and the asset equations for the worker and the firm (2) and (4) gives the following result ${ }^{19}$

$$
\beta J(\gamma, p)=(1-\beta)(W(\gamma, p)-U(\gamma)) .
$$

Two properties about $p_{\gamma}^{*}$ are useful. Consider a firm and a worker that meet and draw a productivity parameter $p$. Accepting the offer has a value $W(\gamma, p)$ to the worker. If he rejects the offer the worker walks away with $U(\gamma)$. It follows that $p_{\gamma}^{*}$ satisfies

$$
W\left(\gamma, p_{\gamma}^{*}\right)=U(\gamma)
$$

Similarly, if production starts the match has a value $J(\gamma, p)$ to the firm. If the firm does not hire the worker it gets the value of the vacancy $V=0$. Thus, the reservation productivity $p_{\gamma}^{*}$ satisfies

$$
J\left(\gamma, p_{\gamma}^{*}\right)=0 .
$$

The asset equations (2) and (4), and the sharing rule (6) give the first expression for $w(\gamma, p)$ :

$$
w(\gamma, p)=\beta h(\gamma) p+(1-\beta)(r+\mu) U(\gamma)
$$

Evaluating the asset equations for the employed worker and the filled job position (2) and (4)

\footnotetext{
${ }^{19}$ In particular, (6) implies that the reservation productivity is the same for workers and firms.
} 
at $p=p_{\gamma}^{*}$, and using (7) and (8) gives

$$
\begin{aligned}
& (r+\mu) U(\gamma)=w\left(\gamma, p_{\gamma}^{*}\right) \\
& h(\gamma) p_{\gamma}^{*}=w\left(\gamma, p_{\gamma}^{*}\right)
\end{aligned}
$$

Combining these two properties gives

$$
(r+\mu) U(\gamma)=h(\gamma) p_{\gamma}^{*}
$$

Finally, (9) and (12) give the first expression linking wages $w(\gamma, p)$ and $p_{\gamma}^{*}$ :

$$
w(\gamma, p)=h(\gamma)\left(\beta p+(1-\beta) p_{\gamma}^{*}\right)
$$

The following result simplifies the model.

Proposition 1. The reservation productivity $p_{\gamma}^{*}$ is independent of $\gamma$, i.e. $p_{\gamma}^{*}=p^{*}$.

The proof is included in the theoretical appendix. The assumption of proportional benefits $b h(\gamma)$ is crucial for this result. Intuitively, in the wage bargaining process the worker expects to be compensated for giving up $U(\gamma)$. While the value of output $h(\gamma) p$ decreases with unemployment, the value of benefits $b h(\gamma)$ does too. The first process raises the reservation productivity, as better matches are required if $h(\gamma)$ is low, and the second lowers it. Given that all quantities are proportional to $h(\gamma)$ these two opposing effects cancel out, and the reservation productivity stays constant. I formally prove this by guessing a solution and proving that the guess is correct. By contrast, as I show in section 4, when benefits are constant this result disappears. With constant benefits $b$, the worker expects to be compensated for giving up $b$, but the value of expected output $h(\gamma) p$ decreases with unemployment. Workers and firms then require better matches for longer unemployment histories. However, it is worth noting that while the reservation productivity is constant and independent of unemployment history, the reservation wage is given by $h(\gamma) p^{*}$ and is decreasing in unemployment history.

Proposition 1 gives the following wage expression

$$
w(\gamma, p)=h(\gamma)\left(\beta p+(1-\beta) p^{*}\right)
$$


Next, I derive the $M m$ ratio to assess the amount of wage dispersion generated by the model.

\subsection{The $M m$ ratio}

As work by Hornstein, Krusell \& Violante (2011) shows, in most search models one can derive the $M m$ ratio without assuming any distribution for match-specific productivities $F(p)$. This property represents a major advantage over other measures of wage dispersion, such as the variance. I show that the $M m$ ratio in the model displays the same property, and is independent of the distributional assumption for $F(p) .^{20}$

Similar to Hornstein, Krusell \& Violante (2011), I define the replacement ratio as the ratio between unemployment benefits and the average wage, and denote it by $\rho$. Workers receive different unemployment benefits depending on their human capital. As a result, to find the replacement ratio in the labor market, I compare average benefits with average wages. More specifically, $\rho$ is given by $\rho=b \bar{h} / \bar{w}$, where $\bar{h}=E(h(\gamma))$ is the average human capital and $\bar{w}$ the average observed wage, which is given by

$$
\bar{w}=E\left(w(\gamma, p) \mid p \geq p^{*}\right)=\int_{0}^{\infty}\left(\int_{p^{*}}^{p^{\max }} w(\gamma, p) \frac{d F(p)}{1-F\left(p^{*}\right)}\right) d G^{E}(\gamma) .
$$

Taking expectations of wage expression (14), I find that $\bar{w}=\bar{h}\left(\beta \bar{p}+(1-\beta) p^{*}\right)$, where $\bar{p}=$ $E\left(p \mid p \geq p^{*}\right)$ is defined in a similar way

$$
\bar{p}=\int_{p^{*}}^{p^{\max }} p \frac{d F(p)}{1-F\left(p^{*}\right)} .
$$

This implies that

$$
b=\rho\left(\beta \bar{p}+(1-\beta) p^{*}\right)
$$

From equation (14), wages are proportional to the human capital level $h(\gamma)$. Taking the logarithm of (14), and using that $\log (h(\gamma))=-\delta \gamma$, shows that $\log$ wages are linear in unemployment history $\gamma$, with a coefficient $\delta$. Therefore, $h(\gamma)$ can be removed from wages by

\footnotetext{
${ }^{20}$ One of the disadvantages of the $M m$ ratio is its reliance on the minimum observation, which suffers from measurement error. However, as suggested by Hornstein, Krusell \& Violante (2011), one can use the 10th percentile observation instead to minimize measurement error.
} 
controlling for unemployment history in a Mincerian wage regression - this is done in the next section, which contains the empirical part of the paper. The objective of this paper is to show that even after controlling for workers characteristics, and in particular after controlling for unemployment history and $h(\gamma)$, the model generates large amounts of wage dispersion. As a result, I focus on the dispersion in wages net of human capital, $\beta p+(1-\beta) p^{*}{ }^{21}$ Therefore, the $M m$ ratio is given by

$$
M m=\left(\beta \bar{p}+(1-\beta) p^{*}\right) / p^{*}
$$

To derive the $M m$ ratio, use asset equation (4), and wage expression (14) to find

$$
(r+\mu+s) J(\gamma, p)=(1-\beta) h(\gamma)\left(p-p^{*}\right)
$$

Substituting equation (19), the Nash Bargaining sharing rule (6), and (12) into the equation for $U(\gamma)$ given by (1) implies the following expression

$$
\frac{r+\mu+\delta}{r+\mu} p^{*}=b+\beta f \int_{p^{*}}^{p^{\max }} \frac{p-p^{*}}{r+\mu+s} d F(p) .
$$

The above equation allows for a simple expression of the $M m$ ratio

$$
M m=\frac{\frac{r+\mu+\delta}{r+\mu}+\frac{f^{*}}{r+\mu+s}}{\rho+\frac{f^{*}}{r+\mu+s}},
$$

\footnotetext{
${ }^{21}$ Because the model assumes proportional benefits and that workers can have infinite lifetimes, some workers may accumulate infinite unemployment histories. Even though the mass of workers with such extreme unemployment durations is close to zero, these workers' human capital and reservation wage approach zero. As a result, the unconditional $M m$ ratio is infinite. However, the unconditional $M m$ ratio is finite and within observable values if one assumes either finite lifetimes or a lower bound for benefits, without affecting the conditional $M m$ ratio, the focus of the paper. For example, section 4 proves that when benefits are constant the (unconditional) reservation wage $w^{*}$ is always greater than benefits $b$. This implies that the unconditional $M m$ ratio is smaller than $1 / \rho$. With a replacement rate $\rho=0.4$, the unconditional $M m$ ratio is thus lower than 2.5 , well within observed unconditional $M m$ ratios. Intuitively, if part of workers' benefits are constant, workers that accumulate too much unemployment history drop out of the labor force. This induces an upper bound on the amount of unemployment history workers may accumulate (or equivalently a lower bound for human capital), which leads to a bounded and realistic unconditional $\mathrm{Mm}$ ratio. The conditional $\mathrm{Mm}$ ratio is practically the same whether benefits are constant or proportional to human capital, as section 4 proves, so the results for the conditional $\mathrm{Mm}$ ratio are unaffected. Proposition 2 and section 4 provide further details. I am indebted to an anonymous referee for helpful comments and suggestions on this issue.
} 
where $f^{*}=f\left(1-F\left(p^{*}\right)\right)$ is the job finding probability. ${ }^{22}$ The appendix shows how to derive the $M m$ ratio from (20) in more detail.

Expression (21) shows that the $M m$ ratio measures wage dispersion without relying on any distributional assumption for $F(p)$. While it depends on the job finding rate $f^{*}=f\left(1-F\left(p^{*}\right)\right)$, this rate is eventually determined by the data, and no functional assumption for $F(p)$ is required. Further, substituting $\delta=0$ yields the same $M m$ ratio as in the Pissarides (1985) model. ${ }^{23}$

The relationship between the job finding and separation rates and the $M m$ ratio is intuitive. With higher $f^{*}$, workers find jobs more quickly, and the value of workers' outside option increases. Workers respond to the higher outside option by increasing their reservation productivities, which lowers wage dispersion and the $M m$ ratio. The $M m$ ratio is thus decreasing in $f^{*}$. The separation rate has the opposite effect, so higher separation rates increase the $\mathrm{Mm}$ ratio. Finally, a higher $\delta$ makes unemployment more costly for workers. Workers are willing to lower their reservation productivity to leave unemployment more rapidly, which increases the $M m$ ratio.

One only requires knowledge of $r, \rho, s, f^{*}, \mu$ and $\delta$ to assess the amount of wage dispersion in the model. Reliable estimates for these parameters can be found from data. In the next section, I use micro data to estimate them and quantify the size of wage dispersion in the model.

\section{Empirical work}

I use data from the 1968-1997 waves of the PSID. ${ }^{24}$ The data appendix describes the sample selection. The main motivation for using the PSID is that it follows workers over time. In the model wages depend on workers' unemployment history. Given the panel structure of the PSID, I construct workers' unemployment history to estimate the depreciation rate $\delta$. The panel structure has the further advantage of allowing for fixed effects estimation. There may be some unobserved characteristics that make some workers more productive than others.

\footnotetext{
${ }^{22}$ While job offers arrive at rate $f$, the worker accepts them if $p \geq p^{*}$, which happens with probability $1-F\left(p^{*}\right)$. Therefore, the job finding rate is given by $f^{*}=f\left(1-F\left(p^{*}\right)\right)$.

${ }^{23}$ With $\delta=0$ the $M m$ ratio is given by $M m=\left(1+\frac{f^{*}}{r+\mu+s}\right) /\left(\rho+\frac{f^{*}}{r+\mu+s}\right)$, which is the expression Hornstein, Krusell \& Violante (2011) find for baseline search models. Further, if $\delta=0$ one can see that the model corresponds to the Pissarides (1985) model.

${ }^{24}$ The PSID collected data biennially after 1997 for funding reasons. Therefore, after 1997 information on the number of weeks in unemployment is unavailable for the years without interviews. See the data appendix for more details.
} 
If less productive workers are more likely to be unemployed, the estimation may be biased. By controlling for workers' constant unobserved characteristics, fixed effects estimation solves this problem. Finally, one concern may be that when a worker joins the sample, previous unemployment history is unknown. Fixed-effects again solves this problem. When a worker joins the sample, prior unemployment history remains constant in later observations, so worker fixed effects controls for it.

\subsection{Estimating $\delta$}

In the model, $\delta$ captures the percentage wage loss caused by unemployment history, which consists of the accumulated unemployment spells of the worker. The PSID asks workers how many weeks they were unemployed in the previous year. ${ }^{25}$ I use the answers to this question to construct unemployment history. I include this information into the variable Unhis, which contains unemployment history in months. To estimate $\delta$, I regress the log of wages on Unhis and other covariates $X$ :

$$
\log W=-\delta \text { Unhis }+\beta X+\epsilon .
$$

In the regression above, $\delta$ gives the percentage wage loss for an additional month of unemployment history. Taking the logarithm of the equation for wages in (14) shows that log wages are linear in unemployment history $\gamma$, with a coefficient $\delta$. Therefore, wage equation (14) is the theoretical equivalent to equation (22). As the estimated $\delta$ captures the exact same effect on wages that $\delta$ has in the model, this empirical strategy provides an estimate that can be consistently entered in the model.

The results are included in Table 1. Column (1) corresponds to the regression with worker fixed-effects. Fixed effects regression controls for all constant characteristics, so in column (1) $X$ also includes potential experience (cubic), regional dummies, and one-digit occupational dummies. ${ }^{26}$ The regression gives an estimate for $\delta$ of 0.0122 . I use this value in the rest of the paper.

\footnotetext{
${ }^{25}$ Most PSID questions are retrospective, and ask the household head about the year prior to the interview. For example, in the 1981 wave the PSID asks about the income or hours worked during 1980.

${ }^{26}$ One can also add educational dummies. The results do not change.
} 
To check the robustness of the estimate for $\delta$, I employ a variety of alternative specifications for the regression in (22). The results, shown in Table 1, are very robust. Column (2) gives $\delta$ in the cross-sectional regression, without fixed-effects. Not having fixed-effects, I add several time-invariant regressors to $X$. Covariates $X$ in column (2) include the covariates in column (1), plus race dummies, educational dummies and year-dummies. Column (3) corresponds to the same regression as in column (1), but with two-digit occupation. The regression has fewer observations because it covers only the years 1975-1997, as the PSID did not record two-digit occupations before 1975. However, running column (1) for the same years as in column (3) gives very similar results. ${ }^{27}$ Column (4) includes the quadratic $U n h i s^{2}$. The results are robust and significant by occupation, with estimates for $\delta$ ranging from 0.006 to 0.017 . Including industry does not change the results. ${ }^{28}$

\subsection{Long-lasting effects of unemployment history}

The model in section 2 relies on permanent human capital losses. To investigate whether there is empirical support for this assumption, I regress log wages on two variables. One contains unemployment history in recent years, the other includes any older unemployment history, i.e. prior to what is considered recent years. If losses are long-lasting, older unemployment history should have an effect on wages, and its magnitude should be similar to the one estimated in (22).

I consider the following estimation equation. I regress log wages on total unemployment history in the past 5 years (recent or short-term unemployment history) and on total unemployment history prior to the past 5 years (old or long-term unemployment history). The regression

\footnotetext{
${ }^{27}$ The PSID recontacted heads of households to get the three-digit occupation for 1968-1974, and included the updated data in a supplement. However, using this supplement has some disadvantages. Some people could not be recontacted, so one needs to drop some individuals to use this supplement. If recontact was possible, the PSID asks about events that happened many years before. In any case, as the text points out, one or two digit regressions give very similar results for $\delta$ over the period for which both are available, so this is not an issue.

${ }^{28}$ The PSID does not contain information on firms. It could be that lower wages are associated with higher unemployment history because firms experiencing negative shocks tend to both layoff more workers and pay lower wages if there is rent sharing. However, the analysis is able to identify this for sectors that receive negative shocks. The estimate for $\delta$ barely changes when controlling for industries and its interaction with time dummies. Further, the job displacement literature finds almost the same results when controlling for firm and industry fixed effects. These observations suggest that this should not be a source of concern.
} 
model is given by

$$
\log W=-\delta^{S T} U n h i s^{S T}-\delta^{L T} U n h i s^{L T}+\beta X+\epsilon
$$

where $U n h i s^{S T}$ is unemployment history accumulated in the past 5 years and $U n h i S^{L T}$ is unemployment history prior to the past 5 years. The coefficients $\delta^{S T}$ and $\delta^{L T}$ capture the effect of recent and old unemployment history on wages. Vector $X$ contains the same worker characteristics as in the estimation equation (22).

The results are included in table 1, column (5). As one would expect, recent unemployment has a strong effect on wages, with $\delta^{S T}$ equal to 0.0161 . However, so does old unemployment history. The regression gives an estimate for $\delta^{L T}$ of 0.0104 , which is close to the value for $\delta$ of 0.0122. This means that one month of unemployment history accumulated more than 5 years ago is associated with a $1.04 \%$ wage loss, which is a very persistent effect. The results are similar when one sets 3 or 7 years as the threshold for recent years. These results are consistent with the findings of the job displacement literature and support the assumption of long-lasting effects of unemployment history on wages. ${ }^{29}$

\subsection{Estimating labor-market transition rates}

I now estimate the labor market transition rates. Why not use existing estimates from the literature, such as the values from the CPS in Shimer (2005)? To test the explanatory power of the model, one should compare the $M m$ ratio in the model with its empirical counterpart in the PSID. The model shows a direct link between labor market flows and the $M m$ ratio. If flows are different in the PSID (as they are), using the flows from the CPS would provide a wrong test of the model. Although the evaluation of wage dispersion in this section is very specific to the PSID, later in the paper I explore the amount of wage dispersion in the CPS, and use the values in Shimer (2005).

The estimation strategy is as follows. The PSID gives the worker's employment state at the time of the interview. Using the date of the interview I calculate the time elapsed between interviews. With these two pieces of information I estimate the transition rates as continuous

\footnotetext{
${ }^{29}$ The online appendix studies wage dispersion when workers accumulate some human capital when they are employed in a job, so that human capital losses are less permanent.
} 
time Markov chains. ${ }^{30}$ This probabilistic model arises when workers can find and lose jobs (i.e. change state) between two employment status observations, and they find and lose jobs (change state) with a frequency given by Poisson processes. The last property differentiates the continuous time Markov chain from a simple Markov chain. The assumptions from the probabilistic model are the same as those implicit in the model, so the estimates correspond exactly to the variables in the model. I use $E$ and $U$ to denote employed and unemployed workers. The probabilities $P_{E E}(t)$ and $P_{U E}(t)$ of transitions $E E$ and $U E$ when the time between interviews is $t$, taking into account that workers can find and lose jobs between employment status observations, are

$$
\begin{aligned}
& P_{E E}(t)=\frac{f^{*}}{s+f^{*}} e^{-\left(f^{*}+s\right) t}+\frac{s}{s+f^{*}}, \\
& P_{U E}(t)=\frac{s}{s+f^{*}}-\frac{s}{s+f^{*}} e^{-\left(f^{*}+s\right) t} .
\end{aligned}
$$

I apply Maximum Likelihood Estimation to the above expressions. The estimation gives the Poisson rates for the separation and job finding rates $s$ and $f^{*}$.

\subsection{Comparing empirical and model's $M m$ ratio}

To estimate the empirical $M m$ ratio, I use the 50-10 percentile ratio of the residual of log-wages in a Mincerian wage regression. Although the $M m$ ratio is the ratio of the average and the minimum wage, using the 10th percentile reduces the measurement error associated with the minimum observation. I consider the residual of wage regression (22), with fixed effects. Given that the dependent variable is log-wages, one must take the exponential of the residual before extracting the 50 th and 10 th percentiles. The resulting 50-10 percentile ratio has a value of $1.34 .^{31}$

I compare the empirical $M m$ ratio with the one in the model by using expression (21). The $M m$ ratio is uniquely determined by $r, \rho, s, f^{*}, \mu$ and $\delta$. The earlier estimations give $\delta, f^{*}$,

\footnotetext{
${ }^{30}$ See Ross (2007) for an exposition of this type of processes.

${ }^{31}$ Hornstein, Krusell \& Violante (2007) follow a similar approach and find a similar $M m$ ratio for the PSID after controlling for fixed effects. The $M m$ ratio does not change significantly when adding unemployment history because the Mincerian regression in (22) already includes a rich set of worker characteristics that determine human capital. Unemployment history is likely to be correlated with these worker characteristics. Therefore, some of the effects of unemployment history on wages are already captured by other worker characteristics when unemployment history is not included in the regression.
} 
and $s$. Table 2 presents these values, where the flow rates correspond to monthly rates, and the value for $\delta$ to the effect of one month of unemployment history on wages. The value for $\mu$ is consistent with a working life of 40 years on average. I choose the interest rate $r$ to be $5 \%$ on average, which implies a monthly value $r \approx 0.0041$. Finally, I consider the same assumption as in Hornstein, Krusell \& Violante (2011), and use the value in Shimer (2005) for $\rho$ of $0.4 .^{32}$ With these values, the model generates an $M m$ ratio of $1.15 .^{33}$

To provide further evidence of the model's contribution, I compare its $M m$ ratio to the one for $\delta=0$. With $\delta=0$, the model reduces to the Pissarides (1985) model and delivers an $M m$ ratio of 1.04, far below its empirical counterpart. The baseline search model struggles to generate significant wage dispersion, precisely the point made by Hornstein, Krusell \& Violante (2011). While the mechanism of the paper accounts only for some of the wage dispersion observed in the data, comparing the above values for the $M m$ ratio shows that the improvement brought by the model is important.

\subsection{Correcting for selection bias}

Attrition in panels may lead to selection bias problems. Individuals drop from the sample, and the reason may not be random. What determines whether we observe an individual may be correlated with wages. To control for selection bias, I use a version of Heckman (1979) two-steps procedure to correct for selection bias. It consists of using some information that affects the probability of leaving the sample without directly affecting wages. I use the number of children under 18 and marital status as a determinant of whether the individual stays in the sample or not. Intuitively, married workers with young children are less likely to move and leave the sample than non-married workers without children. I exploit the hypothesis that these variables affect the probability of sample selection, but are not directly correlated with wages, to produce

\footnotetext{
${ }^{32}$ Some papers use higher values for $\rho$. Hall \& Milgrom (2008) choose $\rho=0.71$ and Hagedorn \& Manovskii (2008) $\rho \approx 0.955$. As Hornstein, Krusell \& Violante (2011) point out, with higher replacement ratios search models match the volatility of unemployment, but generate less wage dispersion, making the frictional wage dispersion problem worse. In section 6 of the paper I discuss higher replacement ratios in more detail.

${ }^{33}$ The $M m$ ratio is similar when one uses the lower bound of the $95 \%$ confidence interval for the estimate of the depreciation rate as the value for $\delta$ in (21). The results are available upon request.
} 
Heckman's two-step correction term. More specifically, I run the following probit regression

$$
s_{i}^{*}=Z_{i} \gamma+v_{i},
$$

where $s_{i}^{*}$ is the latent variable, such that $s_{i}^{*}>0$ if the worker is present in the sample. Regressors $Z_{i}$ contain the variables in $X$, plus number of children under 18, marital status and number of periods present in the sample. The number of children and marital status are highly significant in the first stage. The Likelihood-Ratio test is included in Table 1. The probit estimation produces the Heckman correction term $\hat{\lambda}$, that is then added as a covariate in (22). Column (6) in Table 1 displays the results. In column (6) $X$ contains the covariates of regression column (2), plus the correction term. The estimates of $\delta$ in columns (2) and (6) are very close, so selection bias does not appear to affect the estimate for $\delta$.

\section{Labor market with constant benefits}

In the previous sections I assumed that unemployed workers receive benefits proportional to their human capital, i.e. they receive $b h(\gamma)$. From this assumption, reservation productivities become independent of unemployment history, thus simplifying the model and allowing for a closed form solution. To understand how this assumption may affect the results, consider the following relationship between benefits and workers' reservation choice. If unemployment benefits are higher, workers' outside option increases in value. Workers respond to this by increasing their reservation productivity. This relation between benefits and workers' reservation choice may suggest that by assuming decreasing benefits workers become less picky, thus potentially driving the results. To address this concern, I develop the model of the previous section, but now with constant unemployment benefits $b$. I analyze how this new assumption affects the $M m$ ratio in the model.

\subsection{Search behavior and labor market outcomes}

Reservation productivities depend on unemployment history $\gamma$, so I can not simplify the notation $p_{\gamma}^{*}$. Equations (1) to (13) remain the same, except that $b h(\gamma)$ should be replaced by $b$. I reproduce here expression (13) for wages, which is the result of combining the asset equation 
of an employed worker (2), the asset equation of a filled vacancy (4), and the surplus sharing rule $(6)$ :

$$
w(\gamma, p)=h(\gamma)\left(\beta p+(1-\beta) p_{\gamma}^{*}\right)
$$

The next proposition characterizes workers' search behavior, and provides some important results about reservation productivities $p_{\gamma}^{*}$. The following results are independent of any distributional assumption for $F(p)$.

Proposition 2. a. There exists $\bar{\gamma}$ such that $p_{\bar{\gamma}}^{*}=p^{\max }$, and the reservation wage of workers with $\gamma=\bar{\gamma}$ is given by $w\left(\bar{\gamma}, p_{\bar{\gamma}}^{*}\right)=b$. Furthermore, $\bar{\gamma}=-\log \left(b / p^{\max }\right) / \delta$.

$\boldsymbol{b}$. The reservation productivity $p_{\gamma}^{*}$ is increasing in $\gamma$.

c. The reservation wage $w\left(\gamma, p_{\gamma}^{*}\right)$ is decreasing in $\gamma$.

Corollary. The job finding probability $f\left(1-F\left(p_{\gamma}^{*}\right)\right)$ is decreasing in $\gamma$.

The proofs are included in the appendix, but I provide some intuition here. When bargaining over wages, both workers and firms receive their outside option plus a share of the surplus of the match. The worker's outside option $U(\gamma)$ includes the constant benefits $b$, so the worker must always get payments $b$ at the very least. While benefits are constant, the potential output $h(\gamma) p$ decreases with unemployment history. Eventually, if the worker stays unemployed for too long, no matches yield $p$ high enough to cover $b$. At that point no matches are profitable, and the worker drops from the labor force. The proposition shows in result (a) that if unemployment history goes beyond $\bar{\gamma}$, workers leave the labor force. A similar mechanism explains result (b) that $p_{\gamma}^{*}$ is increasing in $\gamma$. Benefits $b$ are constant, but output $h(\gamma) p$ and the surplus of the match decrease with higher unemployment history $\gamma$. The higher $\gamma$ gets, the better matches are required for the match to be profitable. In the model of previous sections, assuming decreasing benefits $b h(\gamma)$ pushed down the reservation productivities by lowering the worker's outside option $U(\gamma) \cdot{ }^{34}$ Result (c) in the proposition shows that, while the reservation productivity is increasing in unemployment history, the reservation wage is decreasing in unemployment history, as one would expect from empirical observations. Finally, the result of the corollary,

\footnotetext{
${ }^{34}$ The additional assumption that benefits are proportional to $h(\gamma)$ gives the constant reservation productivity in section 2 .
} 
that the job finding probability is decreasing with $\gamma$, follows from the increasing reservation productivity.

\subsection{Reservation productivities}

Because the reservation productivity $p_{\gamma}^{*}$ depends on $\gamma$ if benefits are constant, a closed form expression is not straightforward. Further, one needs to assume a distribution for match-specific productivities $F(p)$ to be able to solve the model. To simplify the calculations I assume that $F(p)$ follows a uniform with support $\left[0, p^{\max }\right] .{ }^{35}$ Given this distributional assumption, I use numerical methods to solve the model. Consider (1), with constant $b$ instead of $b h(\gamma)$, as a differential equation. Integrating it gives the following expression for $U(\gamma)$

$$
U(\gamma)=\frac{b}{r+\mu}+f \int_{\gamma}^{\bar{\gamma}} e^{-(r+\mu)(\Gamma-\gamma)}\left(\int_{p_{\Gamma}^{*}}^{p^{\max }}(W(\Gamma, p)-U(\Gamma)) d F(p)\right) d \Gamma
$$

Substituting wage expression (27) into the asset equation for $J(\gamma, p)$ gives

$$
(r+\mu+s) J(\gamma, p)=(1-\beta) h(\gamma)\left(p-p_{\gamma}^{*}\right)
$$

Given the above equation and the Nash Bargaining sharing rule (6), the expression for $U(\gamma)$ in (28) becomes

$$
p_{\gamma}^{*} h(\gamma)=b+\int_{\gamma}^{\bar{\gamma}} e^{-(r+\mu)(\Gamma-\gamma)}\left(\alpha \int_{p_{\Gamma}^{*}}^{p^{\max }} h(\Gamma)\left(p-p_{\Gamma}^{*}\right) d F(p)\right) d \Gamma,
$$

where $\alpha=\beta f(r+\mu) /(r+\mu+s)$. Equation (30) provides a way of solving for $p_{\gamma}^{*}$ numerically. Using numerical integration and iteration methods I find $p_{\gamma}^{*}$ for a grid $\left\{\gamma_{1}=0, \gamma_{2}, \ldots, \gamma_{n}=\bar{\gamma}\right\}$ of the possible unemployment histories $[0, \bar{\gamma}]$. The theoretical appendix provides the details of the computational strategy.

\footnotetext{
${ }^{35}$ The parameter $p^{\max }$ plays no role in the results, because independently of its value $p_{\gamma}^{*}$ and $p^{\text {max }}$ keep the same ratio. Its value would matter if one introduces endogenous and exogenous separations, and is interested in matching their empirical values, as in Pissarides (2009).
} 


\subsection{Endogenous distributions $G^{U}(\gamma)$ and $G^{E}(\gamma)$}

With constant benefits, deriving the $M m$ ratio requires knowledge of the endogenous distributions of unemployment histories. I use $G^{U}(\gamma)$ and $G^{E}(\gamma)$ to denote their cumulative density functions for unemployed and employed workers, and $N$ and $E$ for the number of unemployed and employed workers.

To find the endogenous distribution of $\gamma$, I look at the flows in the labor market. Unemployed workers find jobs at a rate $f\left(1-F\left(p_{\gamma}^{*}\right)\right)$, employed workers lose their jobs at rate $s$, and all workers leave the labor force at rate $\mu$. Workers leaving the labor force are replaced by new entrants with zero unemployment history.

First, consider the group of unemployed workers with unemployment history lower than $\gamma$. In steady-state, a stationary distribution requires that the flows in and out of this group be equal. For $\gamma \leq \bar{\gamma}$, this condition gives the following flow equation

$$
\begin{aligned}
& g^{U}(\gamma) N+f\left(\int_{0}^{\gamma} 1-F\left(p_{\gamma}^{*}\right) d G^{U}(\gamma)\right) N+\mu G^{U}(\gamma) N= \\
& =s G^{E}(\gamma) E+\mu(E+N) .
\end{aligned}
$$

The left-hand side corresponds to flows out of the group of unemployed workers with unemployment history lower than $\gamma$. The first term represents the workers in that group who have exactly $\gamma$ unemployment history; the second term those who find a job; and the third term those who leave the labor force. The right-hand side of (31) captures the flows in. The first term are the employed workers with unemployment history lower than $\gamma$ who lose their jobs, and the last term are the new entrants (they have zero unemployment history).

Similarly, consider now the group of employed workers with unemployment history lower than $\gamma$. In steady-state, for $\gamma \leq \bar{\gamma}$, the following flow equation holds

$$
(s+\mu) G^{E}(\gamma) E=f\left(\int_{0}^{\gamma}\left(1-F\left(p_{\gamma}^{*}\right)\right) d G^{U}(\gamma)\right) N .
$$

The intuition is similar. The left-hand side of (32) captures the flows out of the group of employed workers with unemployment history lower than $\gamma$, and the right-hand side are the flows in. 
When $\gamma>\bar{\gamma}$, only workers with unemployment history lower than $\bar{\gamma}$ find jobs. ${ }^{36}$ Similar equations to (31) and (32) hold for $\gamma>\bar{\gamma}$

$$
\begin{aligned}
& g^{U}(\gamma) N+f\left(\int_{0}^{\bar{\gamma}}\left(1-F\left(p_{\gamma}^{*}\right)\right) d G^{U}(\gamma)\right) N+\mu G^{U}(\gamma) N= \\
& =s G^{E}(\bar{\gamma}) E+\mu(E+N),
\end{aligned}
$$

and

$$
(s+\mu) G^{E}(\bar{\gamma}) E=f\left(\int_{0}^{\bar{\gamma}}\left(1-F\left(p_{\gamma}^{*}\right)\right) d G^{U}(\gamma)\right) N
$$

To simplify the exposition, I define $\Phi(\gamma)$ as

$$
\Phi(\gamma)=\mu\left(\frac{f\left(1-F\left(p_{\gamma}^{*}\right)\right)+s+\mu}{s+\mu}\right) .
$$

The flow equations shown above give a solution for the density $g^{U}(\gamma)$. For $\gamma \leq \bar{\gamma}$

$$
g^{U}(\gamma)=g^{U}(\bar{\gamma}) \exp \left(\int_{\gamma}^{\bar{\gamma}} \Phi(y) d y\right)
$$

and for $\gamma>\bar{\gamma}$

$$
g^{U}(\gamma)=g^{U}(\bar{\gamma}) e^{\mu(\bar{\gamma}-\gamma)}
$$

The derivations are included in the appendix. To find the final expression for the densities, I derive $g^{U}(\bar{\gamma})$ by using the following identities:

$$
\begin{aligned}
& G^{U}(\bar{\gamma})=g^{U}(\bar{\gamma}) \int_{0}^{\bar{\gamma}} \exp \left(\int_{\Gamma}^{\bar{\gamma}} \Phi(y) d y\right) d \Gamma \\
& 1-G^{U}(\bar{\gamma})=\frac{1}{\mu} g^{U}(\bar{\gamma}) .
\end{aligned}
$$

The above equations result from integrating (36) between 0 and $\bar{\gamma}$, and (37) between $\bar{\gamma}$ and infinity.

\footnotetext{
${ }^{36}$ The results would be the same if workers are replaced after $\bar{\gamma}$ by new workers with zero unemployment history.
} 
Given that $g^{U}(\gamma)$ is known now, I derive $G^{E}(\gamma)$ by using (32) and (34):

$$
G^{E}(\gamma)=\frac{\int_{0}^{\gamma} 1-F\left(p_{\Gamma}^{*}\right) d G^{U}(\Gamma)}{\int_{0}^{\bar{\gamma}} 1-F\left(p_{\Gamma}^{*}\right) d G^{U}(\Gamma)}
$$

The density $g^{E}(\gamma)$ follows by taking derivative:

$$
g^{E}(\gamma)=\frac{\left(1-F\left(p_{\gamma}^{*}\right)\right)}{\int_{0}^{\bar{\gamma}} 1-F\left(p_{\Gamma}^{*}\right) d G(\Gamma)} g^{U}(\gamma)
$$

\subsection{Calibration}

Before evaluating wage dispersion in the model I need to calibrate $b$ and $f$. I choose two targets. In line with the choice for the replacement ratio $\rho$ in the previous sections, the first target imposes that $\rho$ be around 0.4 , so benefits $b$ must be around $40 \%$ of average wages $\bar{w}$. Average wages are given by

$$
\bar{w}=\int_{0}^{\bar{\gamma}}\left(\int_{p_{\Gamma}^{*}}^{p^{\max }} w(\Gamma, p) \frac{d F(p)}{1-F\left(p_{\gamma}^{*}\right)}\right) d G^{E}(\Gamma) .
$$

Given this expression for average wages, the target requires $b / \bar{w}=0.4$.

The second target imposes that the job finding probability in the model must match its empirical counterpart. Thus, I choose the value $f$ for which the average job finding rate $f^{e}=$ $f \int_{0}^{\bar{\gamma}} 1-F\left(p_{\Gamma}^{*}\right) d G^{U}(\gamma)$ equals the empirical estimate from the PSID, i.e. such that $f^{e}=0.159$. These two targets, and the rest of equations in the model, give unique values for $b$ and $f$.

\subsection{The $M m$ ratio with constant benefits}

Figure 1 depicts the reservation productivities $p_{\gamma}^{*}$ as a function of unemployment history $\gamma$ over its support $[0, \bar{\gamma}]$. As proven in proposition 2, the reservation productivity is increasing in $\gamma$, and when $\gamma=\bar{\gamma}$ it reaches the maximum value $p^{\max }$. Figure 2 shows the probability density function $g^{E}(\gamma)$ as a function of $\gamma$, also over its support $[0, \bar{\gamma}]$.

Similar to the model with proportional benefits, wages are proportional to the human capital level $h(\gamma)$, with $w(\gamma, p)=h(\gamma)\left(\beta p+(1-\beta) p_{\gamma}^{*}\right)$. The focus of the paper is on residual wage dispersion, and given that one can remove $h(\gamma)$ in wage regressions, I focus on the wage disper- 
sion generated by $\beta p+(1-\beta) p_{\gamma}^{*}$. Using that the lowest reservation productivity corresponds to $\gamma=0$, the $M m$ ratio is given by

$$
M m=\int_{0}^{\bar{\gamma}}\left(\int_{p_{\Gamma}^{*}}^{p^{\max }}\left(\beta p+(1-\beta) p_{\Gamma}^{*}\right) \frac{d F(p)}{1-F\left(p_{\Gamma}^{*}\right)}\right) d G^{E}(\Gamma) / p_{0}^{*}
$$

For the model with constant benefits, the $M m$ ratio has a value of around 1.16. Table 3 summarizes the several results found for the $\mathrm{Mm}$ ratio.

Although unemployment punishes workers less when benefits are constant, the $\mathrm{Mm}$ ratio is higher than that of the model with proportional benefits. To understand why, consider workers with unemployment history below and above average. Workers with below average unemployment history are less picky, and have lower reservation productivity, whereas the opposite is true for workers with above average unemployment history. Given that the model tries to match a replacement ratio of $40 \%$, to match this target workers with below average unemployment history become less picky than workers in the model with proportional benefits. Because the $M m$ ratio relies on the lowest reservation productivity, this mechanism increases the $M m$ ratio. However, the resulting increase is mild, because workers with below average unemployment history behave in a very similar way than workers in the model with proportional benefits. Given that the distribution of workers is very concentrated on workers with low unemployment history, who have very similar reservation productivities compared to the proportional benefits model, this barely affects the average productivity. In particular, if $b$ is chosen to match the replacement ratio in the model with proportional benefits, the same $b$ almost matches the replacement ratio when benefits are constant, because a large mass of workers (those with low unemployment history) have almost the same reservation productivity.

\section{Extending the exercise to the economy at large}

Up to this point, the quantitative assessment of wage dispersion has been very specific to the PSID. While the PSID was constructed to be representative of the US economy, one wonders how the results extend to other larger data sets, such as the CPS. This question gains interest if one compares the labor market flows in both data sets. The estimates for the job finding and separation rates from the PSID and the CPS show that the PSID is a more stable sample 
of workers than the CPS. Both the job finding and separation rates are smaller in the PSID, but relative to the separation rate the job finding rate is higher in the PSID. In light of these observations, I explore the amount of wage dispersion consistent with CPS labor market flows.

I focus on the CPS because its size and characteristics make it very representative of the US labor market. Among other things, it provides the estimates for the unemployment rate in the US, and the estimates in Shimer (2005) for the job finding and job separation rates, which are the standard reference in the literature. Hornstein, Krusell \& Violante (2011) use the values in Shimer (2005) to assess wage dispersion in search models, so choosing the CPS allows for further comparison between their results and those of this paper.

Similar to Hornstein, Krusell \& Violante (2011), I assign a value of 0.43 to the job finding rate, and a value of 0.03 to the separation rate. I use the value for $\delta$ from the PSID, and the value for $\mu$ that is consistent with a working life of 40 years. The $M m$ ratio increases to around 1.21 and 1.22 with proportional and constant benefits. Intuitively, if $\mu$ and $\delta$ are constant, what matters for wage dispersion is the relative size of $f^{*}$ and $s .{ }^{37}$ As discussed earlier, while both $f^{*}$ and $s$ are higher in the CPS, the ratio $f^{*} / s$ is higher in the PSID. ${ }^{38}$ Thus the increase in the $M m$ ratio.

With CPS labor flows, the $M m$ ratio is around 1.05 for the baseline random matching model, which corresponds to the model with $\delta=0$. Using the same labor market flows, I find that the model with loss of human capital during unemployment gives an $M m$ ratio of up to 1.22. Empirically, the 50-10 percentile ratio in the CPS is between 1.7 and 1.9. Some wage dispersion remains unexplained, but the model explains between $24 \%$ and $31 \%$ of the observed residual wage dispersion in the CPS. This an important improvement over the baseline model, which can only explain $6 \%$ of observed wage dispersion.

\section{Adding on-the-job search}

In baseline search models, workers hold their jobs until separation occurs, so workers must go through unemployment to change jobs. Hornstein, Krusell \& Violante (2011) show that adding on-the-job search increases wage dispersion among identical workers. Intuitively, if workers

\footnotetext{
${ }^{37}$ Or the average job finding rate $f^{e}$ in the case of constant benefits.

${ }^{38}$ That a labor outcome depends on the ratio of $f^{*}$ and $s$ is not surprising, for example in search models the unemployment rate also depends on the ratio rather than the separate values.
} 
can search for jobs when they are employed, they still hold the option to search when they accept a job offer. Therefore, unemployed workers are willing to accept lower wages and wage dispersion increases. The size of the increase depends on how frequently employed workers receive job offers relative to unemployed workers. Hornstein, Krusell \& Violante (2011) find wage dispersion for a search model with on-the-job search using a value for the arrival rate of offers on the job that is consistent with empirical job-to-job transitions. The magnitude of the $M m$ ratio is similar to the one of the model with loss of human capital during unemployment, between 1.16 and 1.27. In the next section I combine both features in a search model.

\subsection{The labor market}

I assume now that workers also search on the job in the model with unemployment history and proportional benefits $b h(\gamma)$ of section 2. Unemployed workers receive job offers at rate $f^{u}$, and employed workers receive job offers at rate $f^{w}$. The asset equations for unemployed workers (1) and vacancies (3) remain the same. The equation for employed workers is now given by

$$
\begin{gathered}
(r+\mu) W(\gamma, p)=w(\gamma, p)+f^{w} \int_{p}^{p^{\max }}(W(\gamma, y)-W(\gamma, p)) d F(y) \\
-s(W(\gamma, p)-U(\gamma))
\end{gathered}
$$

Compared to (2), equation (44) captures that workers now also receive job offers at a rate $f^{w}$. If the productivity is above the current level $p$ they change jobs. Similarly, the asset equation for a filled vacancy is now given by

$$
(r+\mu) J(\gamma, p)=h(\gamma) p-w(\gamma, p)-\left(s+f^{w}(1-F(p))\right)(J(\gamma, p)-V)
$$

Intuitively, firms get a net flow $h(\gamma) p-w(\gamma, p)$. The job is destroyed either because of separation, which happens with frequency $s$, or because the worker finds a better job, which happens with frequency $f^{w}(1-F(p))$.

As in section 2, reservation productivities are independent of unemployment history $\gamma$, so $p_{\gamma}^{*}=p^{*}$. This simplifies the model and allows for a closed form expression of wage dispersion. The proof proceeds in the same way as in the proof of proposition 1. The intuition is similar. 
All payments, both during employment and unemployment, are proportional to the human capital level $h(\gamma)$. As a result, unemployment history $\gamma$ is irrelevant for workers' reservation decision.

\subsection{The $M m$ ratio}

Using the asset equations one gets that wages are of the form $w(\gamma, p)=h(\gamma) \hat{w}(p)$, where $\hat{w}(p)$ is independent of $\gamma$. This shows that, as in the model with human capital losses during unemployment, log wages are linear in unemployment history with coefficient $\delta$. Given the focus of the paper on wage dispersion among identical workers, I control for unemployment history in the empirical exercise and focus on the wage dispersion of $\hat{w}(p)$.

For a given $F(p)$, workers move jobs once they become employed. I denote $G(p)$ the endogenous distribution of match productivities. The average of $\hat{w}(p)$, which I denote $\overline{\hat{w}}=E(\hat{w}(p) \mid p>$ $\left.p^{*}\right)$, is thus given by

$$
\overline{\hat{w}}=\int_{p^{*}}^{p^{\max }} \hat{w}(y) d G(y) .
$$

Equation (11) gives that $w\left(\gamma, p^{*}\right)=h(\gamma) p^{*}$, so the $M m$ ratio is given by

$$
M m=\overline{\hat{w}} / p^{*} .
$$

Using the asset equation for unemployed workers (1) and the asset equation for employed workers (44) evaluated at $p=p^{*}$ gives the following equation

$$
\begin{aligned}
& h(\gamma) p^{*}+f^{w} \int_{p^{*}}^{p^{\max }}(W(\gamma, y)-U(\gamma)) d F(y)= \\
& =\frac{r+\mu}{r+\mu+\delta}\left(b h(\gamma)+f^{u} \int_{p^{*}}^{p^{\max }}(W(\gamma, y)-U(\gamma)) d F(y)\right) .
\end{aligned}
$$

Combining this equation with the other equations in the model gives the $M m$ ratio

$$
M m=\frac{1+\frac{\left(\frac{r+\mu}{r+\mu+\delta}\right) f^{u}-f^{w}}{r+\mu+s+f^{w}}}{\left(\frac{r+\mu}{r+\mu+\delta}\right) \rho+\frac{\left(\frac{r+\mu}{r+\mu+\delta}\right) f^{u}-f^{w}}{r+\mu+s+f^{w}}},
$$


where $f^{u}$ is the job finding probability and $f^{w}$ is the rate at which job offers arrive on the job. ${ }^{39}$ The appendix includes the details of the derivation.

By shutting down the appropriate channel, expression (49) also provides the $M m$ ratio for the baseline search model, the model with unemployment history and the on-the-job search model. If $\delta=0$, the unemployment history mechanism is shut down and (49) gives the expression for the $M m$ ratio in the on-the-job search model. If $f^{w}=0$, on-the-job search is shut down and (49) corresponds to (21). Finally, setting both $\delta=0$ and $f^{w}=0$ gives the $M m$ ratio for the baseline search model.

\subsection{Quantifying the model's $M m$ ratio}

Wage dispersion, as measured by the $M m$ ratio in (49), depends uniquely on a few parameters, $r, \rho, s, \mu, f^{u}, f^{w}$ and $\delta$. Further, it is independent of any distributional assumption about $F(p)$. The relationship between these parameters and wage dispersion is the same as before, only that now wage dispersion further depends on the arrival rate of offers on the job $f^{w}$. Large values of $f^{w}$ imply that it is easier to switch jobs, making the option value of searching on the job larger. Workers thus accept lower wages and wage dispersion increases.

I use the CPS values for $f^{u}$ and $s$. To quantify wage dispersion in the model, the expression for the $M m$ ratio requires a value for the arrival rate $f^{w}$. Similar to Hornstein, Krusell \& Violante (2011), I follow Nagypal (2008) and choose the value for $f^{w}$ that is consistent with empirical job-to-job transitions. Using data from the Survey of Income and Program Participation (SIPP), Nagypal (2008) finds monthly job-to-job flows of around $2.2 \%$. This implies a value for $f^{w}$ of around $0.07 .^{40}$ The other parameters are chosen in the same way as in section 5 . The model generates an $M m$ ratio of around 2.07, and accounts for all of the observed residual wage dispersion.

\footnotetext{
${ }^{39}$ Given the paper's focus on the steady state, without loss of generality I assume that $F\left(p^{*}\right)=0$ for the derivation of the $M m$ ratio. Therefore $f^{u}$ is the job finding rate. This assumption makes the exposition simpler, but the results are exactly the same without it.

${ }^{40}$ Empirical job-to-job transitions can be found in Fallick \& Fleischman (2004), Moscarini \& Vella (2008) and Nagypal (2008). I use the lowest value, which corresponds to Nagypal (2008), to show that even with this value wage dispersion is substantial.
} 


\subsection{Frictional wage dispersion and cyclical unemployment fluctua- tions}

Hornstein, Krusell \& Violante (2011) show that in search models frictional wage dispersion and unemployment volatility are closely related. ${ }^{41}$ The baseline search model usually requires high values of the replacement ratio to match the cyclical volatility of unemployment. However, high values of the replacement ratio make the frictional wage dispersion problem worse. Intuitively, if benefits are higher relative to average wages the value of workers' outside option increases. Workers wait longer to accept a job offer and wage dispersion decreases. Therefore, in search models there is a trade-off between matching the unemployment volatility and generating sizable wage dispersion.

I calculate the $M m$ ratio in the model with both on-the-job search and unemployment history for the different values of the replacement ratio $\rho$ used in the literature. Shimer (2005) uses a value of 0.40 , which is the value Hornstein, Krusell \& Violante (2011) and the previous sections use. Hall \& Milgrom (2008) choose $\rho=0.71$ based on data on the elasticity of labor supply. Hagedorn \& Manovskii (2008) calibrate vacancy costs to get the highest value in the literature, around $0.95 .^{42}$

Table 5 gives the $M m$ ratio for the three values of the replacement ratio. The $M m$ ratio is 2.07 with a replacement ratio of $0.40,1.84$ if the replacement ratio is 0.71 , and 1.68 for the highest replacement ratio of 0.95 . Therefore, even for the highest value of the replacement ratio the amount of wage dispersion is large. Although some wage dispersion remains unexplained for higher values of the replacement ratio, the model with both on-the-job search and unemployment history accounts for almost all of the observed residual wage dispersion.

\section{Concluding Remarks}

Motivated by the findings of Hornstein, Krusell \& Violante (2011) that baseline search models fail to generate significant wage dispersion, this paper investigates how much wage dispersion

\footnotetext{
${ }^{41}$ See Shimer (2005), Mortensen \& Nagypal (2007) and Pissarides (2009) for more details on the unemployment volatility puzzle.

${ }^{42}$ Although as Costain \& Reiter (2008) and Hall \& Milgrom (2008) point out, with this very high value labor supply becomes very responsive to unemployment benefits.
} 
arises if workers lose some skills during unemployment. I develop a search model in which workers gradually lose some human capital while they stay unemployed. The wage losses caused by unemployment matter for workers' search behavior. Knowing that unemployment hurts their earnings, workers lower their reservation productivity and accept lower wages to leave unemployment more quickly. The paper shows that the model generates significant wage dispersion among identical workers and is an important improvement over baseline search models. Using the measure proposed by Hornstein, Krusell \& Violante (2011), the $M m$ ratio, I find a closed form expression for wage dispersion that depends only on a few parameters. Combining the theoretical predictions of the model and estimates from micro data, the model explains between $45 \%$ and $48 \%$ of the observed residual wage dispersion in the PSID, and between $24 \%$ and $31 \%$ of that in the CPS. By contrast, the baseline model accounts for around $11 \%$ for the PSID, and $6 \%$ for the CPS. When workers also search on-the-job the model accounts for most of the observed residual wage dispersion. Even for high values of non-market time the search framework with both unemployment history and on-the-job search generates large amounts of wage dispersion. The paper thus addresses the trade-off in search models between matching frictional wage dispersion and the cyclical behavior of unemployment and vacancies.

In recessions jobs become scarce, unemployment rises, and workers take longer to find jobs. The results of this paper suggest that, by accounting for workers' human capital depreciation during unemployment, the welfare losses in recessions may be larger than previously thought. In the context of the recent crisis, the consequences for workers' labor market prospects have been dramatic, suggesting that one should take these costs into account. 


\section{References}

Blanchard, O. J. \& Diamond, P. (1994), 'Ranking, unemployment duration, and wages', The Review of Economic Studies 61(3), pp. 417-434.

Burdett, K., Carrillo-Tudela, C. \& Coles, M. G. (2011), 'Human capital accumulation and labor market equilibrium', International Economic Review 52(3), 657-677.

Carrington, W. J. (1993), 'Wage losses for displaced workers: Is it really the firm that matters?', The Journal of Human Resources 28(3), pp. 435-462.

Coles, M. \& Masters, A. (2000), 'Retraining and long-term unemployment in a model of unlearning by not doing', European Economic Review 44(9), 1801 - 1822.

Costain, J. S. \& Reiter, M. (2008), 'Business cycles, unemployment insurance, and the calibration of matching models', Journal of Economic Dynamics and Control 32(4), 1120 - 1155.

Couch, K. A. \& Placzek, D. W. (2010), 'Earnings losses of displaced workers revisited', American Economic Review 100(1), 572-89.

den Haan, W. J., Haefke, C. \& Ramey, G. (2005), 'Turbulence and unemployment in a job matching model', Journal of the European Economic Association 3(6), 1360-1385.

Fallick, B. C. (1996), 'A review of the recent empirical literature on displaced workers', Industrial and Labor Relations Review 50(1), pp. 5-16.

Fallick, B. C. \& Fleischman, C. A. (2004), 'Employer-to-employer flows in the U.S. labor market: the complete picture of gross worker flows'. Finance and Economics Discussion Series 2004-34. Board of Governors of the Federal Reserve System (U.S.).

Farber, H. S. (1997), 'The changing face of job loss in the united states, 19811995', Brookings Papers on Economic Activity: Microeconomics pp. 55-128.

Hagedorn, M. \& Manovskii, I. (2008), 'The cyclical behavior of equilibrium unemployment and vacancies revisited', The American Economic Review 98(4), pp. 1692-1706.

Hall, R. E. \& Milgrom, P. R. (2008), 'The limited influence of unemployment on the wage bargain', The American Economic Review 98(4), pp. 1653-1674.

Heckman, J. J. (1979), 'Sample selection bias as a specification error', Econometrica 47(1), pp. $153-161$.

Hornstein, A., Krusell, P. \& Violante, G. L. (2007), 'Frictional wage dispersion in search models: A quantitative assessment'. NBER wp 13674.

Hornstein, A., Krusell, P. \& Violante, G. L. (2011), 'Frictional wage dispersion in search models: A quantitative assessment', American Economic Review 101(7), 2873-98. 
Jacobson, L. S., LaLonde, R. J. \& Sullivan, D. G. (1993), 'Earnings losses of displaced workers', The American Economic Review 83(4), pp. 685-709.

Jacobson, L. S., LaLonde, R. J. \& Sullivan, D. G. (2005), 'Estimating the returns to community college schooling for displaced workers', Journal of Econometrics 125(1-2), 271 - 304.

Judd, K. (1998), Numerical Methods in Economics, MIT Press, Cambridge.

Kletzer, L. G. (1998), 'Job displacement', The Journal of Economic Perspectives 12(1), pp. 115-136.

Ljungqvist, L. \& Sargent, T. J. (1998), 'The european unemployment dilemma', Journal of Political Economy 106(3), 514-550.

Ljungqvist, L. \& Sargent, T. J. (2007), 'Understanding european unemployment with matching and search-island models', Journal of Monetary Economics 54(8), 2139 - 2179.

Ljungqvist, L. \& Sargent, T. J. (2008), 'Two questions about european unemployment', Econometrica 76(1), 1-29.

Machin, S. \& Manning, A. (1999), Chapter 47: The causes and consequences of longterm unemployment in europe, Vol. 3, Part C of Handbook of Labor Economics, Elsevier, pp. 3085 $-3139$.

Mortensen, D. T. (2005), Wage Dispersion: Why Are Similar Workers Paid Differently?, MIT Press: Zeuthen Lecture Book Series, Cambridge, Massachusetts.

Mortensen, D. T. \& Nagypal, E. (2007), 'More on unemployment and vacancy fluctuations', Review of Economic Dynamics 10(3), 327 - 347.

Mortensen, D. T. \& Pissarides, C. A. (1994), 'Job creation and job destruction in the theory of unemployment', Review of Economic Studies 61(0), 397-415.

Mortensen, D. T. \& Pissarides, C. A. (1998), 'Technological progress, job creation, and job destruction', Review of Economic Dynamics 1(4), 733 - 753.

Moscarini, G. \& Vella, F. (2008), 'Occupational mobility and the business cycle'. NBER wp 13819.

Mukoyama, T. \& Sahin, A. (2009), 'Why did the average duration of unemployment become so much longer?', Journal of Monetary Economics 56(2), 200 - 209.

Nagypal, E. (2008), 'Worker reallocation over the business cycle: The importance of job-to-job transitions'. mimeo, Northwestern University. 
Neal, D. (1995), 'Industry-specific human capital: Evidence from displaced workers', Journal of Labor Economics 13(4), pp. 653-677.

Pavoni, N. (2011), 'Optimal unemployment insurance, with human capital depreciation, and duration dependence', International Economic Review .

Pavoni, N. \& Violante, G. L. (2007), 'Optimal welfare-to-work programs', The Review of Economic Studies 74(1), 283-318.

Pissarides, C. A. (1985), 'Short-run equilibrium dynamics of unemployment, vacancies, and real wages', American Economic Review 75(4), pp. 676-690.

Pissarides, C. A. (1992), 'Loss of skill during unemployment and the persistence of employment shocks', The Quarterly Journal of Economics 107(4), pp. 1371-1391.

Pissarides, C. A. (2000), Equilibrium Unemployment Theory, MIT Press, Cambridge.

Pissarides, C. A. (2009), 'The unemployment volatility puzzle: Is wage stickiness the answer?', Econometrica 77(5), 1339-1369.

Postel-Vinay, F. \& Robin, J. (2002), 'Equilibrium wage dispersion with worker and employer heterogeneity', Econometrica 70(6), 2295-2350.

Ross, S. M. (2007), Introduction to probability models, Academic Press. 9th Edition.

Ruhm, C. J. (1991), 'Are workers permanently scarred by job displacements?', The American Economic Review 81(1), pp. 319-324.

Schoeni, R. \& Dardia, M. (2003), 'Estimates of earnings losses of displaced workers using california administrative data'. University of Michigan Population Studies Center Report 03543.

Shimer, R. (2005), 'The cyclical behavior of equilibrium unemployment and vacancies', American Economic Review 95(1), 24-49.

Shimer, R. \& Werning, I. (2006), 'On the optimal timing of benefits with heterogeneous workers and human capital depreciation'. mimeo, University of Chicago.

Stevens, A. H. (1997), 'Persistent effects of job displacement: The importance of multiple job losses', Journal of Labor Economics 15(1), pp. 165-188.

Topel, R. (1990), 'Specific capital and unemployment: Measuring the costs and consequences of job loss', Carnegie-Rochester Conference Series on Public Policy 33(0), 181 - 214.

von Wachter, T., Song, J. \& Manchester, J. (2009), 'Long-term earnings losses due to mass layoffs during the 1982 recession: An analysis using U.S. administrative data from 1974 to 2004'. mimeo, Columbia University. 


\section{Theoretical Appendix - Not for Publication}

\section{Proof of proposition 1}

The proof proceeds by guessing a solution and then confirming the guess. Guessing that $U(\gamma)=$ $h(\gamma) U$, with $U$ independent of $\gamma$. Given the guess, I use now that $(r+\mu) U(\gamma)=h(\gamma) p_{\gamma}^{*}$ to get

$$
p_{\gamma}^{*}=(r+\mu) U
$$

which is independent of $\gamma$. In the text I use $p^{*}$ to denote the reservation productivity. Substituting these results in (1), the asset equation for $U(\gamma)$, gives a unique solution for $U$. Given that the Bellman equation has a unique solution (it is a contraction), this proves the result.

\section{Derivation of the $M m$ ratio}

The text shows that taking expectations of (14) gives that $\bar{w}=\overline{h(\gamma}\left(\beta \bar{p}+(1-\beta) p^{*}\right)$, where $\bar{p}$

is defined by $\bar{p}=E\left(p \mid p \geq p^{*}\right)=\int_{p^{*}}^{p^{\max }} p \frac{d F(p)}{1-F\left(p^{*}\right)}$. Further, because $\rho=b h \overline{(\gamma)} / \bar{w}$, we also have that $b=\rho\left(\beta \bar{p}+(1-\beta) p^{*}\right)$. The $M m$ ratio is given by $(21)$, which I reproduce here

$$
M m=\left(\beta \bar{p}+(1-\beta) p^{*}\right) / p^{*} .
$$

Denote the job finding rate $f\left(1-F\left(p^{*}\right)\right)$ by $f^{*}$. Using (20) one can derive the $M m$ ratio in the following way

$$
\begin{aligned}
& \frac{r+\mu+\delta}{r+\mu} p^{*}=b+\beta f^{*} \int_{p^{*}}^{p^{\max }} \frac{p-p^{*}}{r+\mu+s} \frac{d F(p)}{1-F\left(p^{*}\right)} \\
& \left(\frac{r+\mu+\delta}{r+\mu}+\frac{f^{*}}{r+\mu+s}\right) p^{*}=\left(\rho+\frac{f^{*}}{r+\mu+s}\right)\left(\beta \bar{p}+(1-\beta) p^{*}\right)
\end{aligned}
$$

where the second equation is obtained using that $\beta\left(p-p^{*}\right)=\left(\beta p+(1-\beta) p^{*}\right)-p^{*}$. The expression for $M m$ in the text results from rearranging the last equation. 


\section{$M m$ ratio with unemployment history and human capital accumula- tion during employment}

This section extends the model in section 2 and allows workers to accumulate human capital when they are employed. Workers recover some of the human capital they lose during unemployment, so human capital losses are not fully permanent. Assume that human capital depreciates at a constant rate $\delta_{u}$ during unemployment, and appreciates at a rate $\delta_{e}$ when workers are employed. As a result, employment history - the cumulative duration of employment spells - becomes a new state variable. An important restriction on $\delta_{e}$ is that it must not exceed the effective discount rate $r+\mu$, otherwise the present value of wage payments is infinite. Denote unemployment and employment history by $\gamma_{u}$ and $\gamma_{e}$. The assumptions about the human capital process imply that $h\left(\gamma_{u}, \gamma_{e}\right)=e^{\delta_{e} \gamma_{e}-\delta_{u} \gamma_{u}}$. As in the model with unemployment history, benefits are proportional to human capital $h\left(\gamma_{u}, \gamma_{e}\right)$, so unemployed workers receive $b h\left(\gamma_{u}, \gamma_{e}\right)$. Following the same procedure as in proposition 1, it is straightforward that the value functions are proportional to human capital $h\left(\gamma_{u}, \gamma_{e}\right)$, and that the reservation productivity is independent of $\left(\gamma_{u}, \gamma_{e}\right)$. The Bellman equations are given by

$$
\begin{aligned}
& (r+\mu) U\left(\gamma_{u}, \gamma_{e}\right)=b h\left(\gamma_{u}, \gamma_{e}\right)+f \int_{p^{*}}^{p^{\max }}\left(W\left(\gamma_{u}, \gamma_{e}, y\right)-U\left(\gamma_{u}, \gamma_{e}\right)\right) d F(y)-\delta_{u} U\left(\gamma_{u}, \gamma_{e}\right), \\
& (r+\mu) W\left(\gamma_{u}, \gamma_{e}, p\right)=w\left(\gamma_{u}, \gamma_{e}, p\right)-s\left(W\left(\gamma_{u}, \gamma_{e}, p\right)-U\left(\gamma_{u}, \gamma_{e}\right)\right)+\delta_{e} W\left(\gamma_{u}, \gamma_{e}, p\right), \\
& (r+\mu) J\left(\gamma_{u}, \gamma_{e}, p\right)=h\left(\gamma_{u}, \gamma_{e}\right) p-w\left(\gamma_{u}, \gamma_{e}, p\right)-s J\left(\gamma_{u}, \gamma_{e}, p\right)+\delta_{e} J\left(\gamma_{u}, \gamma_{e}, p\right),
\end{aligned}
$$

where $p^{*}$ is the reservation productivity, which is independent of $\left(\gamma_{u}, \gamma_{e}\right)$. Use $S\left(\gamma_{u}, \gamma_{e}, p\right)$ to denote the match surplus, i.e. $S\left(\gamma_{u}, \gamma_{e}, p\right) \equiv J\left(\gamma_{u}, \gamma_{e}, p\right)+W\left(\gamma_{u}, \gamma_{e}, p\right)-U\left(\gamma_{u}, \gamma_{e}\right)$. Combining the Bellman equations gives

$$
\left(r+s-\delta_{e}\right) S\left(\gamma_{u}, \gamma_{e}, p\right)=h\left(\gamma_{u}, \gamma_{e}\right) p-\left(r-\delta_{e}\right) U\left(\gamma_{u}, \gamma_{e}\right)
$$


Given that $W\left(\gamma_{u}, \gamma_{e}, p^{*}\right)=U\left(\gamma_{u}, \gamma_{e}\right)$ and $J\left(\gamma_{u}, \gamma_{e}, p^{*}\right)=0$, the Bellman equations imply that

$$
\begin{aligned}
& \left(r-\delta_{e}\right) U\left(\gamma_{u}, \gamma_{e}\right)=w\left(\gamma_{u}, \gamma_{e}, p^{*}\right), \\
& w\left(\gamma_{u}, \gamma_{e}, p^{*}\right)=h\left(\gamma_{u}, \gamma_{e}\right) p^{*} .
\end{aligned}
$$

Combining the above two results with the expression for the surplus gives

$$
S\left(\gamma_{u}, \gamma_{e}, p\right)=\frac{h\left(\gamma_{u}, \gamma_{e}\right) \cdot\left(p-p^{*}\right)}{r+\mu+s-\delta_{e}}
$$

Similar to the Pissarides model, I assume that the worker and the firm share the surplus according to a Nash Bargaining rule, so

$$
\beta J\left(\gamma_{u}, \gamma_{e}, p\right)=(1-\beta)\left(W\left(\gamma_{u}, \gamma_{e}, p\right)-U\left(\gamma_{u}, \gamma_{e}\right)\right)
$$

where $\beta$ is workers' bargaining strength. Substituting the value functions $W$ and $J$ leads to the following expression for wages

$$
w\left(\gamma_{u}, \gamma_{e}, p\right)=h\left(\gamma_{u}, \gamma_{e}\right)\left(\beta p+(1-\beta) p^{*}\right)
$$

Substituting the above results into the Bellman equation for $U\left(\gamma_{u}, \gamma_{e}\right)$ leads to the expression

$$
\left(\frac{r+\mu+\delta_{u}}{r+\mu-\delta_{e}}\right) h\left(\gamma_{u}, \gamma_{e}\right) p^{*}=b h\left(\gamma_{u}, \gamma_{e}\right)+f^{*} \int_{p^{*}}^{p^{\max }} \frac{w\left(\gamma_{u}, \gamma_{e}, y\right)-w^{*}}{r+\mu+s-\delta_{e}} \cdot \frac{d F(y)}{1-F\left(p^{*}\right)}
$$

where $w^{*} \equiv w\left(\gamma_{u}, \gamma_{e}, p^{*}\right)$ is the reservation wage and $f^{*} \equiv f\left(1-F\left(p^{*}\right)\right)$ is the job finding rate.

As in the model with unemployment history, the focus of the paper is on residual wage dispersion. Given that wages are proportional to human capital $h(\gamma)$ and that unemployment history is observable, human capital $h\left(\gamma_{u}, \gamma_{e}\right)$ can be removed from wages using a Mincerian regression, as is done in the empirical part of the paper-section 3. Using $\hat{w} \equiv w / h$ to denote the wage net of human capital, one can simplify human capital from (A5) to get

$$
\left(\frac{r+\mu+\delta_{u}}{r+\mu-\delta_{e}}\right) p^{*}=b+f^{*} \int_{p^{*}}^{p^{\max }} \frac{\hat{w}(y)-p^{*}}{r+\mu+s-\delta_{e}} \cdot \frac{d F(y)}{1-F\left(p^{*}\right)} .
$$


The $M m$ ratio is given by $M m=\overline{\hat{w}} / p^{*}$, where

$$
\overline{\hat{w}} \equiv E\left(\hat{w} \mid p \geq p^{*}\right)=\int_{p^{*}}^{p^{\max }} \hat{w}(y) d F(y) /\left(1-F\left(p^{*}\right)\right)
$$

is the observed average wage net of human capital $h(\gamma)$. Integrating the above expression gives

$$
\left(\frac{r+\mu+\delta_{u}}{r+\mu-\delta_{e}}\right) p^{*}=b+\frac{f^{*}}{r+\mu+s-\delta_{e}}\left(\overline{\hat{w}}-p^{*}\right) .
$$

Rearranging gives the $M m$ ratio

$$
M m=\frac{\frac{r+\mu+\delta_{u}}{r+\mu-\delta_{e}}+\frac{f^{*}}{r+\mu+s-\delta_{e}}}{\rho+\frac{f^{*}}{r+\mu+s-\delta_{e}}} .
$$

From (A6), one can recover the $M m$ ratio in the baseline model, the model with unemployment history and the model with returns to experience by setting the appropriate rate to zero. Substituting $\delta_{e}=0$ into (A6) gives the $M m$ ratio with unemployment history, as given by (21) in the main text. When $\delta_{u}=0,(\mathrm{~A} 6)$ gives the $M m$ ratio for the model with returns to experience in Hornstein et al. (2011), equation (6). Finally, setting $\delta_{e}=\delta_{u}=0$ delivers the $M m$ ratio in the baseline search model.

Wage dispersion increases in the model with both unemployment history and returns to experience. Clearly, if we set $\delta_{u}$ equal to the depreciation rate $\delta$ in the model with unemployment history in section 2, the $M m$ ratio in (A6) is always strictly greater than the one with unemployment history alone given by (21). However, to allow for comparison between the extended model in this section and the one in the main text, I consider the case where $\delta=\delta_{e}+\delta_{u}$. With this assumption, compared to an employed worker the human capital of an unemployed worker depreciates at the same rate in both models. ${ }^{43}$ As I show below, for standard parameter values wage dispersion increases as well. Substitute $\delta=\delta_{e}+\delta_{u}$ into (A6), which gives

$$
M m=\frac{\frac{r+\mu+\delta-\delta_{e}}{r+\mu-\delta_{e}}+\frac{f^{*}}{r+\mu+s-\delta_{e}}}{\rho+\frac{f^{*}}{r+\mu+s-\delta_{e}}} .
$$

\footnotetext{
${ }^{43}$ With returns to experience, if a worker is unemployed her human capital depreciates at rate $\delta_{u}$, whereas if she were employed her human capital would appreciate at a rate $\delta_{e}$. With unemployment history alone, an unemployed worker loses human capital at a rate $\delta=\delta_{u}+\delta_{e}$, whereas her human capital would remain constant if she were employed.
} 
Take derivative with respect to $\delta_{e}$ to get

$$
\frac{\partial M m}{\partial \delta_{e}}=\frac{\rho\left[\delta\left(r+\mu+s-\delta_{e}\right)^{2}+f^{*}\left(r+\mu-\delta_{e}\right)^{2}\right]-f^{*}\left[\left(r+\mu-\delta_{e}\right)^{2}-\delta s\right]}{\left(r+\mu-\delta_{e}\right)^{2}\left[\rho\left(r+\mu+s-\delta_{e}\right)+f^{*}\right]^{2}} .
$$

The sign of the above derivative is ambiguous, but for standard parameter values it is clearly positive. ${ }^{44}$ Intuitively, there are two effects at play when $\delta_{e}$ increases (and as result $\delta_{u}$ decreases). First, an increase in $\delta_{e}$ lowers $\delta_{u}$, which lowers wage dispersion. Second, an increase in $\delta_{e}$ lowers the rate at which future payment flows are discounted, because of human capital accumulation. This lowers the reservation productivity and increases wage dispersion. Equation (A8) shows that for standard parameter values the drop in the reservation productivity clearly dominates, so overall wage dispersion increases.

Given $\delta=0.0122$ from the empirical work in section 3, to quantify wage dispersion the only parameter left to calibrate is $\delta_{e}$. I follow Hornstein et al. (2011) and set $\delta_{e}=0.0017$ monthly, which implies that wages double over workers' working life. With this value and the Shimer (2005) values for the job finding and separation rates, the $M m$ ratio equals 1.258 , whereas it equals 1.209 when workers do not accumulate human capital during employment (i.e. when $\left.\delta_{e}=0\right)$. On the other hand, with returns to experience and no human capital depreciation during unemployment, the $M m$ ratio equals only 1.076. This shows that the depreciation of human capital due to unemployment history is an important mechanism that generates sizable amounts of wage dispersion.

\section{Proof of proposition 2}

Proof of $\boldsymbol{a}$. The proof proceeds by contradiction. Function $h(\gamma)$ is decreasing in $\gamma$ and tends to zero as $\gamma$ tends to infinity (remember, $h(\gamma)=e^{-\delta \gamma}$ ). Therefore, there exists a $\bar{\gamma}$ such that $h(\bar{\gamma}) p^{\max }=b$, and $h(\gamma) p^{\max }<b$ for all $\gamma>\bar{\gamma}$. Suppose now that part $(a)$ of the proposition is not true, and $p_{\bar{\gamma}}^{*}<p^{\max }$. Then

$$
p_{\bar{\gamma}}^{*} h(\bar{\gamma})<h(\bar{\gamma}) p^{\max }=b
$$

\footnotetext{
${ }^{44}$ In particular, $\delta s-(r+\mu)^{2} \leq-\left[\left(r+\mu-\delta_{e}\right)^{2}-\delta s\right]$, since $0 \leq \delta_{e}<r+\mu$. If $\delta s-(r+\mu)^{2}>0$, the derivative $\partial \mathrm{Mm} / \partial \delta_{e}$ is always positive. For standard calibrations $\delta s-(r+\mu)^{2}>0$ is clearly satisfied.
} 
From (11) we know that $p_{\bar{\gamma}}^{*} h(\bar{\gamma})=w\left(\gamma, p_{\bar{\gamma}}^{*}\right)$. It is clear from the Nash bargaining sharing rule that the worker is always compensated for his outside option $U(\gamma)$, so workers must get at the very least the stream of payments $b$ (one can see this more formally by solving (1) as a differential equation). As a result $w\left(\gamma, p_{\gamma}^{*}\right) \geq b$ for all $\gamma$, so combining this with the above gives

$$
b \leq p_{\bar{\gamma}}^{*} h(\bar{\gamma})<h(\bar{\gamma}) p^{\max }=b,
$$

which is a contradiction. Taking $\bar{\gamma}$ as defined earlier proves the first part of part (a). By definition of $\bar{\gamma}, h(\bar{\gamma}) p^{\max }=b$. Combining this with $p_{\bar{\gamma}}^{*} h(\bar{\gamma})=w\left(\gamma, p_{\bar{\gamma}}^{*}\right)$ and $p_{\bar{\gamma}}^{*}=p^{\max }$ gives the second result in $a$. Finally, taking logarithm of $h(\bar{\gamma}) p^{\max }=b$ and rearranging gives the expression for $\bar{\gamma}$.

Proof of $\boldsymbol{b}$. First, define the total surplus of a match as $S(\gamma, p)=J(\gamma, p)+W(\gamma, p)-U(\gamma)$, for $p \geq p_{\gamma}^{*}$. The Nash Bargaining sharing rule implies that workers and firms get their outside option plus their share of the total surplus ( $\beta$ for the worker, $1-\beta$ for the firm). As potential output is decreasing in $\gamma$, it is clear that the surplus is decreasing in $\gamma$.

Now assume that there exist $\gamma_{0}$ and $\gamma_{1}$ such that $\gamma_{0}<\gamma_{1}$ and $p_{\gamma_{0}}^{*}>p_{\gamma_{1}}^{*}$. This assumption implies that $J\left(\gamma_{1}, p_{\gamma_{0}}^{*}\right)>0$, as $J(\gamma, p)>0$ for all $p>p_{\gamma}^{*}$. But $J$ is decreasing in $\gamma$, and given the assumption $p_{\gamma_{0}}^{*}>p_{\gamma_{1}}^{*}, J\left(\gamma_{1}, p_{\gamma_{0}}^{*}\right)$ is well defined and $J\left(\gamma_{1}, p_{\gamma_{0}}^{*}\right)<J\left(\gamma_{0}, p_{\gamma_{0}}^{*}\right)=0$. This is a contradiction, thus $p_{\gamma}^{*}$ is non-decreasing in $\gamma$. That $p_{\gamma}^{*}$ is not constant can be readily seen from the expression for $U(\gamma)$.

Proof of $\boldsymbol{c}$. I prove first that if some function $\pi(\gamma)$ is non-increasing, i.e. $\pi^{\prime}(\gamma) \leq 0$ for all $\gamma$, then the function $\Pi(\gamma)=\int_{\gamma}^{\bar{\gamma}} e^{-r(\Gamma-\gamma)} \pi(\Gamma) d \Gamma$ is decreasing in $\gamma$. Intuitively, $\Pi(\gamma)$ is the present value of the stream of payments $\pi$ between $\gamma$ and the final period $\bar{\gamma}$. If these payments are decreasing $\Pi(\gamma)$ is unambiguously decreasing. I apply the result to the following expression for $U(\gamma)$, that is derived by integrating (1), with constant $b$ instead of $b h(\gamma)$ :

$$
U(\gamma)=\frac{b}{r+\mu}+f \int_{\gamma}^{\bar{\gamma}} e^{-(r+\mu)(\Gamma-\gamma)}\left(\int_{p_{\Gamma}^{*}}^{p^{\max }}(W(\Gamma, p)-U(\Gamma)) d F(p)\right) d \Gamma
$$

This proves that $U(\gamma)$ is decreasing. Since $(r+\mu) U(\gamma)=w\left(\gamma, p_{\gamma}^{*}\right)$, this proves part (c) of the proposition.

To prove that $\Pi(\gamma)$ is decreasing, first observe that $\Pi(\bar{\gamma})=0$, and $\Pi(\gamma)>0$ if $\gamma<\bar{\gamma}$. This 
implies that $\Pi(\gamma)$ must be decreasing near $\bar{\gamma}$. Therefore, if it is not true that $\Pi^{\prime}(\gamma)<0$ for all $\gamma$, there must exists $\gamma_{0}$ such that $\Pi^{\prime}\left(\gamma_{0}\right)=0$. I show that this leads to a contradiction.

Take derivative of $\Pi(\gamma)$ :

$$
\Pi^{\prime}(\gamma)=-\pi(\gamma)+r \int_{\gamma}^{\bar{\gamma}} e^{-r(\Gamma-\gamma)} \pi(\Gamma) d \Gamma
$$

That $\Pi^{\prime}\left(\gamma_{0}\right)=0$ implies that

$$
\pi\left(\gamma_{0}\right)=r \int_{\gamma_{0}}^{\bar{\gamma}} e^{-r\left(\Gamma-\gamma_{0}\right)} \pi(\Gamma) d \Gamma
$$

which further implies that

$$
\Pi\left(\gamma_{0}\right)=\frac{\pi\left(\gamma_{0}\right)}{r}
$$

That $\pi(\gamma)$ is decreasing implies that $\pi\left(\gamma_{0}\right) \geq \pi(\gamma)$ for all $\gamma \geq \gamma_{0}$. Therefore

$$
\Pi\left(\gamma_{0}\right) \geq \int_{\gamma_{0}}^{\bar{\gamma}} e^{-r\left(\Gamma-\gamma_{0}\right)} \pi\left(\gamma_{0}\right) d \Gamma=\frac{\pi\left(\gamma_{0}\right)}{r}\left(1-e^{-r\left(\bar{\gamma}-\gamma_{0}\right)}\right)
$$

The expression above implies that $\Pi\left(\gamma_{0}\right)<\frac{\pi\left(\gamma_{0}\right)}{r}$, leading to a contradiction.

\section{Endogenous distributions $G^{U}(\gamma)$ and $G^{E}(\gamma)$ with constant benefits $b$}

Equation (32) implies

$$
G^{E}(\gamma) E=\frac{f}{s+\mu}\left(\int_{0}^{\gamma} 1-F\left(p_{\gamma}^{*}\right) d G^{U}(\gamma)\right) N
$$

Similarly, using (34) and that $G^{E}(\bar{\gamma})=1$ as no worker is hired if $\gamma>\bar{\gamma}$

$$
E=\frac{f}{s+\mu}\left(\int_{0}^{\bar{\gamma}} 1-F\left(p_{\gamma}^{*}\right) d G^{U}(\gamma)\right) N
$$

Now take the derivative of (31) with respect to $\gamma$ to find

$$
g^{U}(\gamma) N+f\left(1-F\left(p_{\gamma}^{*}\right) g^{U}(\gamma) N+\mu g^{U}(\gamma) N=s g^{E}(\gamma) E\right.
$$


Taking now derivative of (32)

$$
g^{E}(\gamma) E=\frac{f}{s+\mu}\left(1-F\left(p_{\gamma}^{*}\right)\right) g^{U}(\gamma) N
$$

Combining the two equations above gives

$$
\frac{d g^{U}(\gamma)}{d \gamma} N+\left(f\left(1-F\left(p^{*}\right)\right)+\mu\right) g^{U}(\gamma) N=\frac{s}{s+\mu} f\left(1-F\left(p^{*}\right)\right) g^{U}(\gamma) N
$$

which implies the following differential equation

$$
\frac{d g^{U}(\gamma)}{d \gamma}+\Phi(\gamma) g^{U}(\gamma)=0
$$

where $\Phi(\gamma)$ is defined in the text as $\Phi(\gamma)=\mu\left(\frac{f\left(1-F\left(p_{\gamma}^{*}\right)\right)+s+\mu}{s+\mu}\right)$. The solution gives the expression in the text:

$$
g^{U}(\gamma)=g^{U}(\bar{\gamma}) \exp \left(\int_{\gamma}^{\bar{\gamma}} \Phi(y) d y\right)
$$

To find $g^{U}(\gamma)$ for $\gamma>\bar{\gamma}$ I proceed similarly. Taking derivative of (33)

$$
\frac{d g^{U}(\gamma)}{d \gamma} N+\mu g^{U}(\gamma) N=0
$$

This implies the result of the text:

$$
g^{U}(\gamma)=\exp (\mu(\bar{\gamma}-\gamma)) g(\bar{\gamma})
$$

\section{Numerical strategy to find $p_{\gamma}^{*}$}

Consider equation (30). Using the assumption of $F(p)$ being uniform $\left[0, p^{\max }\right]$ gives

$$
p_{\gamma}^{*}=(h(\gamma))^{-1}\left(b+\beta f \frac{r+\mu}{r+\mu+s} \int_{\gamma}^{\bar{\gamma}} e^{-(r+\mu)(\Gamma-\gamma)} h(\Gamma) \frac{\left(p^{\max }-p_{\Gamma}^{*}\right)^{2}}{2 p^{\max }} d \Gamma\right)
$$

I use the following strategy to solve for $p_{\gamma}^{*}$. Consider a grid $\left\{\gamma_{1}=0, \gamma_{2}, \ldots, \gamma_{n}=\bar{\gamma}\right\}$ of the range of unemployment histories $[0, \bar{\gamma}]$. Given an initial guess for the vector of unemployment histories 
$\left\{p_{\gamma_{i}}^{*}\right\}_{i}$, I calculate the integral in the above equation using numerical integration. Entering the result in the above equation gives the new value for $p_{\gamma}^{*}$. Iterating until convergence provides the solution for $p_{\gamma}^{*}$.

See Judd (1998) for a bound on the size of the error involved in the numerical integration. This error decreases as the grid uses more nodes. However, as the strategy combines numerical integration and iteration methods, the final bound on the error is not straightforward. To assess the error involved in this numerical strategy, I test how well it approximates a known solution. This provides, in the language of Judd (1998), some backward error analysis. Consider the general case of the equation above

$$
f(\gamma)=a_{1}(\gamma)+a_{2}(\gamma) \int_{\gamma}^{\bar{\gamma}} \phi(\Gamma, f(\Gamma)) d \Gamma
$$

The method described earlier provides a solution for this general case. For the case where the $a_{i}$ are constant and $\phi(\Gamma, f(\Gamma))=f(\Gamma)$ an exact solution exists. Comparing the exact solution to the one provided by the numerical strategy shows that the numerical solution can get as close as necessary to the exact solution within a reasonable time.

\section{$M m$ ratio with on the job search}

Using the asset equations wages are given by $w(\gamma, p)=h(\gamma) \hat{w}(p)$, and similarly $W(\gamma, p)=$ $h(\gamma) \hat{W}(p)$. The paper investigates wage dispersion among identical workers, so I focus on the dispersion of $\hat{w}(p)$, the wage adjusted for human capital. The $M m$ ratio is given by

$$
M m=\overline{\hat{w}} / p^{*}
$$

where

$$
\overline{\hat{w}}=\int_{p^{*}}^{p^{\max }} \hat{w}(y) d G(y)
$$

Using integration by parts one gets

$$
\overline{\hat{w}}=[\hat{w}(y) G(y)]_{p^{*}}^{p^{\max }}-\int_{p^{*}}^{p^{\max }} \hat{w}^{\prime}(y) G(y) d y
$$


Given that $G(p)$ is the endogenous distribution of observed productivities, $G\left(p^{\max }\right)$ is 1 and $G\left(p^{*}\right) 0$ is 0 . Using that $\hat{w}\left(p^{*}\right)=p^{*}$ gives

$$
\overline{\hat{w}}=p^{*}+\int_{p^{*}}^{p^{\max }} \hat{w}^{\prime}(y)(1-G(y)) d y
$$

Using the asset equations gives

$$
(r+\mu+s) \hat{W}^{\prime}(p)=\hat{w}^{\prime}(p)+f^{w}\left(0+\int_{p^{*}}^{p^{\max }}-\hat{W}^{\prime}(p) d F(y)\right)
$$

which implies the following expression

$$
\left(r+\mu+f^{w}(1-F(p))\right) \hat{W}^{\prime}(p)=\hat{w}^{\prime}(p)
$$

Use asset equations $U(\gamma)$ and $W\left(\gamma, p^{*}\right)$ to get expression (48), which after dividing by $h(\gamma)$ and rearranging becomes

$$
p^{*}=\frac{r+\mu}{r+\mu+\delta} b+\left(f^{u} \frac{r+\mu}{r+\mu+\delta}-f^{w}\right) \int_{p^{*}}^{p^{\max }} \hat{W}^{\prime}(y)(1-F(y)) d y
$$

where the above equation uses that

$$
\int_{p^{*}}^{p^{\max }}\left(\hat{W}(y)-\hat{W}\left(p^{*}\right)\right) d F(y)=\int_{p^{*}}^{p^{\max }} \hat{W}^{\prime}(y)(1-F(y)) d y
$$

To find the average wage $\overline{\hat{w}}$ I now derive the endogenous distribution $G(p)$. Given the paper's focus on the steady state, without loss of generality I assume that $F\left(p^{*}\right)=0$. The results are exactly the same without this assumption, but the derivation is simpler. ${ }^{45}$ The interpretation is that $f^{u}$ becomes the job finding rate. Consider the group of employed workers in a job with productivity lower than $p$. In steady state the following flow equation holds

$$
(1-u) G(p)\left(s+f^{w}(1-F(p))\right)=f^{u} F(p) u
$$

\footnotetext{
${ }^{45}$ Reservation productivity $p^{*}$ is constant in steady state. Unless one is interested in business cycle properties, or in how shocks affect the economy, this assumption is irrelevant.
} 
The left-hand side of the above equation are the flows out of the group, and consists of job separations and quits to better jobs with productivity still lower than $p$. The right-hand side are the flows in, which consist of unemployed workers who find a job with productivity lower than $p$. Similarly, in steady state

$$
u f^{u}\left(1-F\left(p^{*}\right)\right)=(1-u) s
$$

These equations imply that

$$
G(p)=F(p)\left(\frac{s}{s+f^{w}(1-F(p)}\right)
$$

Thus

$$
\begin{aligned}
1-G(p) & =\left(\frac{s+f^{w}}{s+f^{w}(1-F(p))}\right)(1-F(p)) \\
& \approx\left(\frac{r+\mu+s+f^{w}}{r+\mu+s+f^{w}(1-F(p))}\right)(1-F(p)),
\end{aligned}
$$

where the last approximation is true if $r$ is small relative to $s$ or $f^{w}$. Substituting the above expression for $1-F\left(p^{*}\right)$ in the equation for $p^{*}$ gives

$$
p^{*}=\frac{r+\mu}{r+\mu+\delta} b+\left(\frac{f^{u} \frac{r+\mu}{r+\mu+\delta}-f^{w}}{r+\mu+s+f^{w}}\right)\left(\overline{\hat{w}}-p^{*}\right)
$$

which gives, noting that $b=\rho \overline{\hat{w}}$, the expression for the $M m$ ratio in the text. 


\section{Data Appendix - Not for Publication}

The Panel Study of Income Dynamics (PSID) started collecting data in 1968. The original PSID consisted of two samples: the core sample, representative of the US population; and the SEO sample, an oversample of low income families. In 1968 the PSID initially followed 5000 families, 3000 of them from the core sample, and the rest from the SEO sample. Since then the PSID has grown in size, as it followed young family members when they formed their own family.

The PSID collected data annually between 1968 and 1997, but biennially after 1997 for funding reasons. Therefore, after 1997 information on the number of weeks in unemployment is unavailable for the years without interviews. ${ }^{46}$ As the empirical work requires knowledge of workers' unemployment history, I only include the 1968-1997 PSID waves, and discard waves after 1997.

Information in the PSID is mostly retrospective. For example, questions about hours worked or income earned refer to the previous calendar year. For example, the year $t$ wave asks about the income earned during year $t-1$. As is standard in the literature, I construct wages by dividing total labor earnings by the number of hours worked.

I now describe the sample choice, which is standard in the literature. I restrict my attention to male workers between 18 and 65 years old in the core sample. I include only observations with positive earnings. Similar to Hornstein, Krusell \& Violante (2011), I exclude observations with too many hours or too few work hours, more specifically, if work hours are lower than 520 or greater than 5096. Excluding these outliers reduces measurement error. I also ignore observations for which the real wage is lower than half the minimum wage of 1982, or with topcoded earnings. I exclude workers in farming or in the army. For the fixed effects estimation only workers with a minimum of 8 observations are included. Finally, I exclude individuals currently self-employed, in school, inactive, or living in Alaska or Hawaii. I drop individuals with inconsistent or missing information. ${ }^{47}$

This selection leaves 2,160 workers, with observations spanning the 30 years between 19681997. In total the sample includes 34,542 observations, or 1,151 worker/year observations.

\footnotetext{
${ }^{46}$ For example, if the worker is interviewed in 1997 and again in 1999, information on number of weeks unemployed in 1998 is unavailable.

${ }^{47}$ Although very few workers are affected by this once I implement the previous selection criteria.
} 


\section{Tables}

Table 1: The EFfects of unemployment HIStory on WAGES

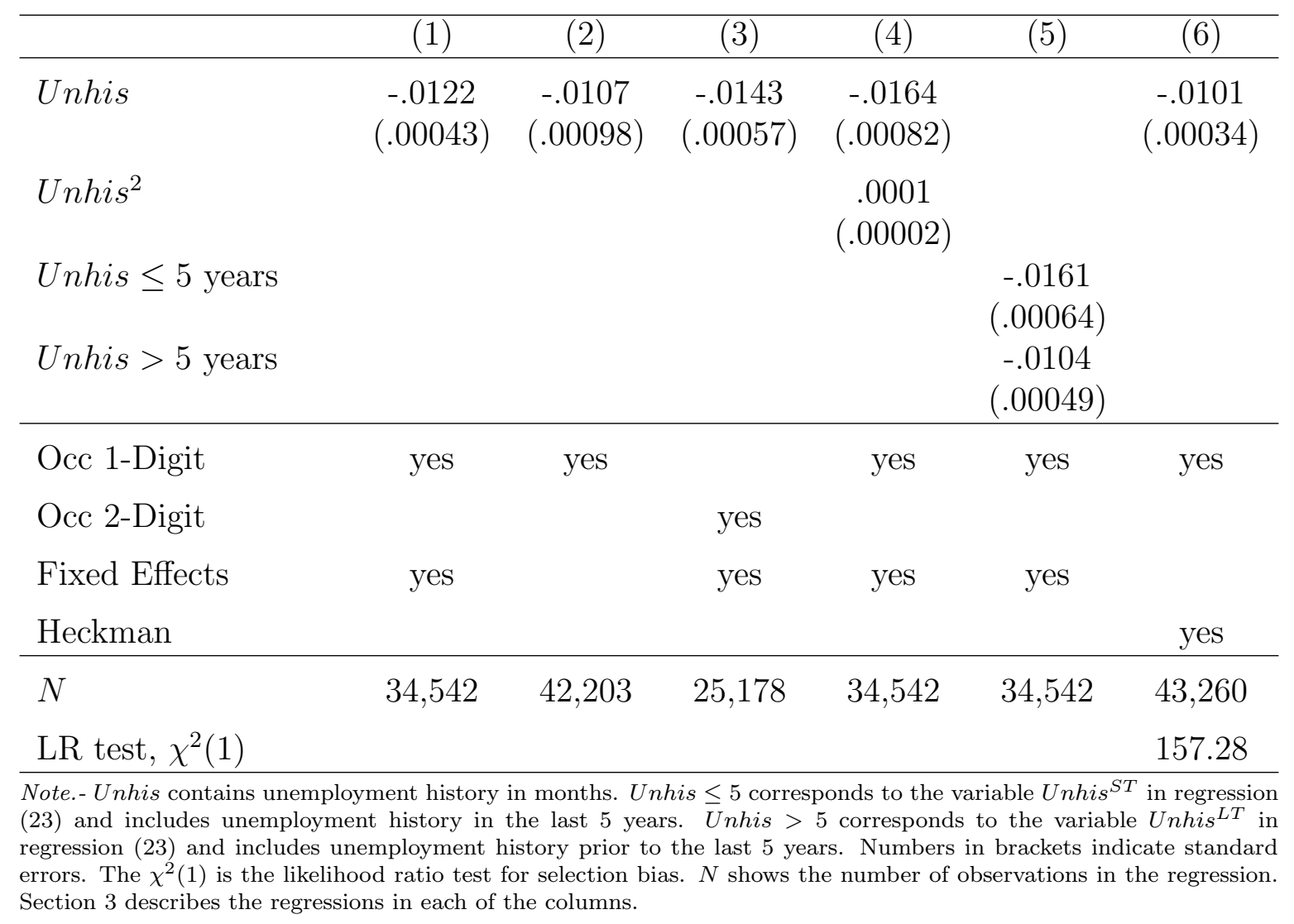


Table 2: Estimates From PSID

\begin{tabular}{lcl}
\hline Parameter & Value & Description \\
\hline$\delta$ & 0.0122 & Depreciation rate of wage during unemployment \\
$f^{*}$ & 0.1591 & Job finding probability \\
$s$ & 0.0035 & Separation rate \\
\hline
\end{tabular}

Note.- These are monthly rates. The depreciation rate $\delta$ is taken from a standard Mincerian regression that includes unemployment history. The job finding and separation rates are estimated using MLE on a continuous time Markov chain. Details of the estimation are included in section 3. 
Table 3: The $M m$ RATio With PSID Flows

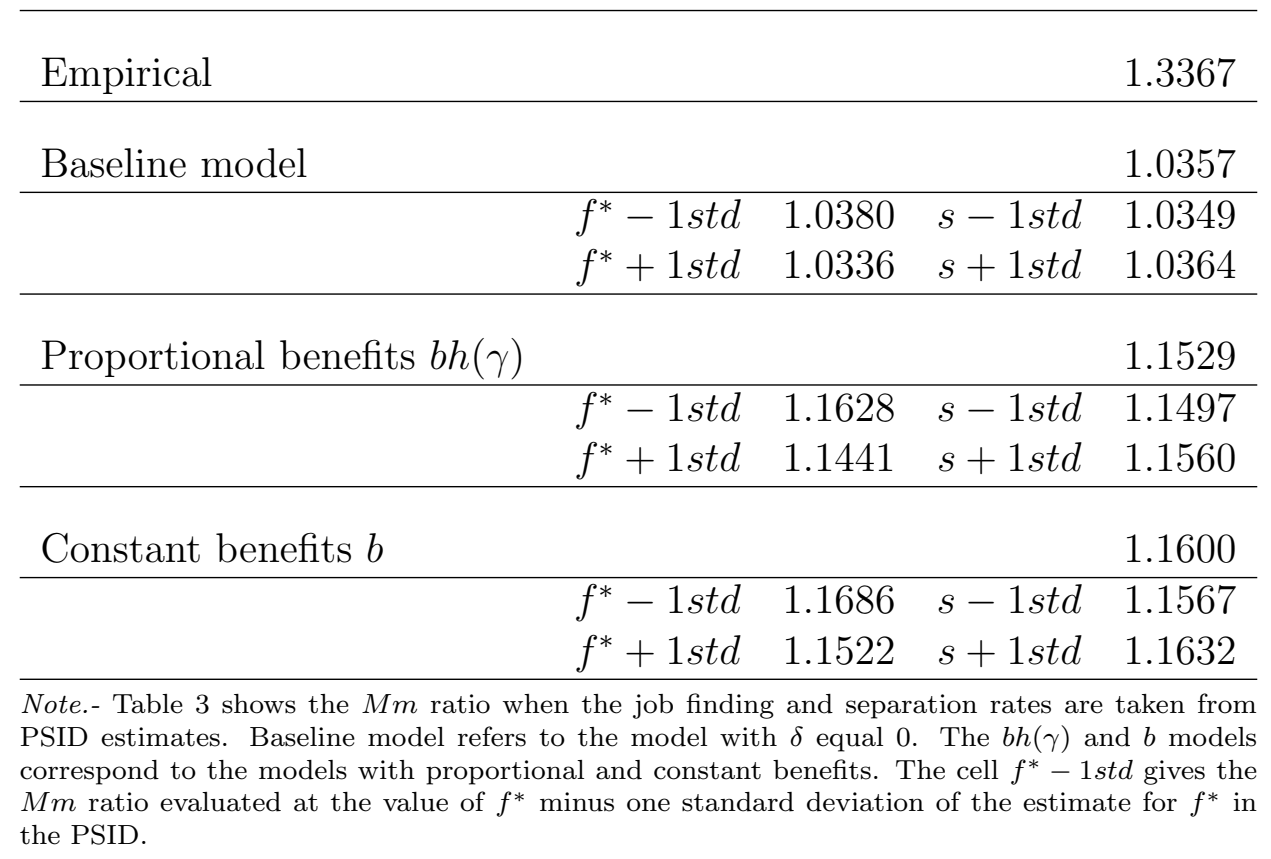


Table 4: The $M m$ RATio With CPS LABOR FLOWS

\begin{tabular}{lc}
\hline Source & $M m$ ratio \\
\hline Empirical & $1.70-1.90$ \\
Baseline model & 1.05 \\
Proportional benefits $b h(\gamma)$ & 1.2095 \\
Constant benefits $b$ & 1.2185 \\
\hline $\begin{array}{l}\text { Note. - Table 4 shows the } M m \text { ratio when the job finding and separation rates are taken } \\
\text { from Shimer }(2005) \text {. Baseline model refers to the model with } \delta \text { equal } 0 . \text { The } b h(\gamma) \text { and } b \\
\text { models correspond to the models with proportional and constant benefits. }\end{array}$
\end{tabular}


Table 5: $M m$ RATio With UnEMPlOyMENT History AND ON-THE-JOB SEARCH

\begin{tabular}{llc}
\hline Calibration source & $\rho$ & $M m$ ratio \\
\hline Shimer (2005) & 0.40 & 2.07 \\
Hall \& Milgrom (2008) & 0.71 & 1.84 \\
Hagedorn \& Manovskii (2008) & 0.95 & 1.68 \\
\hline
\end{tabular}

Note.- The table gives the value of the $\mathrm{Mm}$ ratio for different values of the value of nonmarket time. Section 6 contains further details. 


\section{Figures}

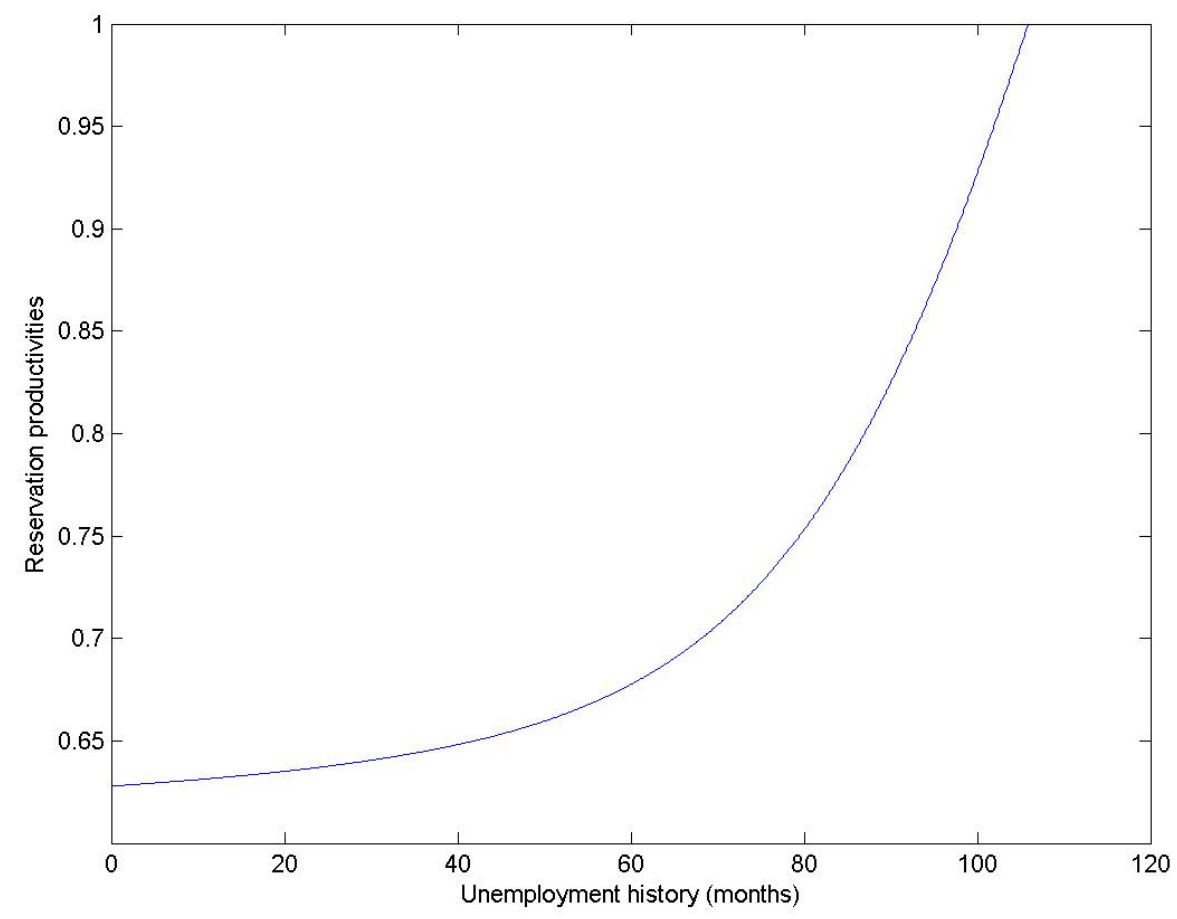

Figure 1: Reservation productivities $p_{\gamma}^{*}$ with constant $b$ 


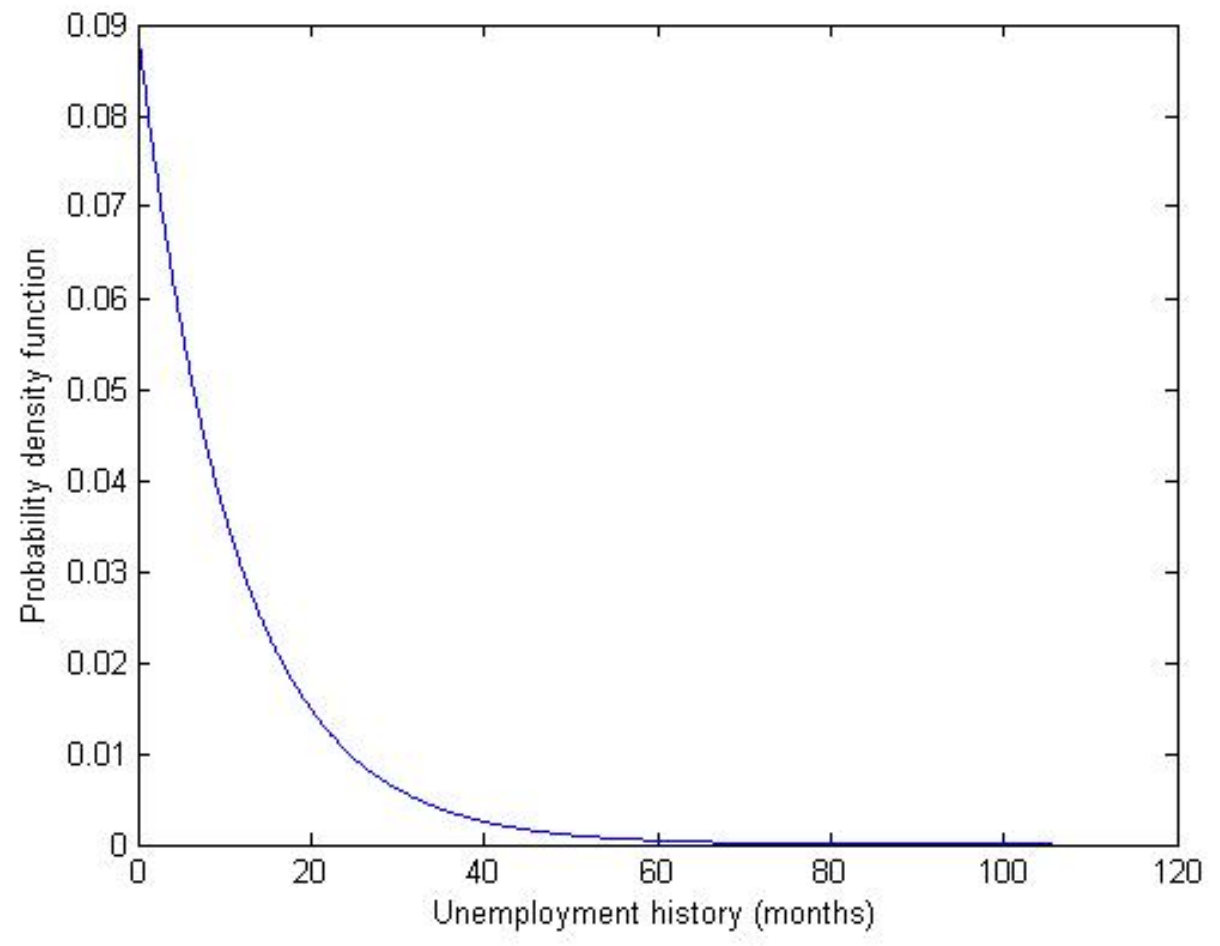

Figure 2: Distribution of unemployment history with constant $b$ 